\title{
Effect of Particle Shape on the Deformation and Stress Reduction of a Gravel Soil Due to Wetting
}

Reza Mahinroosta ( $\nabla$ rmahinroosta@csu.edu.au )

Charles Sturt University

Vahid Oshtaghi

University of Zanjan

\section{Research Article}

Keywords: Angularity, Collapse settlement, Particle breakage, Stress reduction, Wetting

Posted Date: April 27th, 2021

DOI: https://doi.org/10.21203/rs.3.rs-453086/v1

License: (9) This work is licensed under a Creative Commons Attribution 4.0 International License. Read Full License

Version of Record: A version of this preprint was published at Scientific Reports on August 16th, 2021. See the published version at https://doi.org/10.1038/s41598-021-95731-y. 


\title{
Effect of Particle Shape on the Deformation and Stress
}

\section{Reduction of a Gravel Soil due to Wetting}

\author{
Reza Mahinroosta* \\ Senior Lecturer, School of Engineering, Faculty of Business, Justice and Behavioural Sciences, \\ Charles Sturt University, New South Wales, Australia. \\ Institute for Land, Water and Society, Charles Sturt University, NSW, Australia.
}

$\begin{array}{ll}\text { Address: } & \text { School of Engineering, } \\ & \text { Charles Sturt University, } \\ & \text { Panorama Avenue, } \\ & \text { Bathurst NSW 2795, } \\ & \text { Australia. } \\ \text { Email: } & \text { rmahinroosta@csu.edu.au }\end{array}$

Vahid Oshtaghi

Professional Engineer, Civil Engineering Department, Zanjan University, Zanjan, Iran Email: $\quad$ vahidoshtaghi@gmail.com

*Corresponding author. 


\begin{abstract}
In this paper, the effect of particle shape is investigated on the stress reduction and collapse deformation of gravelly soil using medium-scale direct shear test apparatus under different relative densities, normal stress, and shear stress levels. The Micro-Deval test was used to produce sub-angular particles from angular particles with continuous smoothening of the corners of the particles. Two series of soil specimens were obtained with the same rock type, particle size distribution, and relative density but different particle shapes. In addition to traditional direct shear tests on dry and wet specimens, a specific test procedure was applied to explore the stress reduction and collapse of soil specimens due to wetting. For instance, dry soil specimens under several normal pressure were subjected to shear loading while inundated at several levels of shear stresses. The results showed that the stress reduction and settlement due to wetting increased with vertical and shear stress level in both types of particle shapes, with higher values in angular particle shapes. The wetting of the samples had more impact on the particle breakage in angular gravel than sub-angular gravel, which increased linearly with the normal stress.
\end{abstract}

Keywords: Angularity, Collapse settlement, Particle breakage, Stress reduction, Wetting

\title{
Introduction
}

Sudden deformation in granular material due to wetting is called collapse deformation. This usually occurs in recent soil deposits with a high void ratio ${ }^{1}$ and reservoir banks after impoundment ${ }^{2}$. In addition, the soils in the foundation of structures or in the body of embankments may experience high volumetric deformation if they are poorly compacted. Laboratory tests and field instrumentation have shown the possibility of collapse behaviour in a variety of granular material from silt and sand to gravel and rockfill ${ }^{3-8}$. The collapse behaviour of coarse grain material in the upstream zone of embankment dams has a significant effect on the final deformation due to impoundment ${ }^{9}$. The deformation may result in internal erosion, uncontrolled leak from an embankment dam or even rupture of the dam due to localised collapse ${ }^{7}$. Collapse settlement is also important in road construction ${ }^{10}$ and reclaimed lands on which buildings are to be constructed.

There are different reasons for the collapse deformation of granular material, such as sudden reduction in stress state due to addition of water, easier sliding of the soil grains due to inter-particle strength reduction, particle breakage and change in the contact bonding mechanism ${ }^{11}$. For the case of particle breakage, different factors are responsible such as particle size, stress state, previous stress history, relative compaction, particle shapes, rock type and water itself ${ }^{12,13}$. In terms of bonding mechanism, the water menisci play a significant role in the 
collapse of granular soils. Research showed that applying polar liquids different from water can reduce collapse potential by $90 \%{ }^{14}$. With a similar concept, pollutants in the water, e.g. from the leakage of sewage systems, also has a great impact on the surface collapse due to chemical attack to the bonds between the soil particles ${ }^{15}$.

Nobari and Duncan ${ }^{16}$ appear to have been the first researchers who studied the collapse phenomenon and stress reduction in granular materials subjected to wetting. They showed that the collapse deformation of the material was decreased by an increase in the relative density and the moisture content. Alawaji ${ }^{6}$ showed that the collapse deformation of the soil increases with the compressibility of the material and the normal stress. Based on a discrete element modelling of a rockfill column, Silvani, et al. ${ }^{17}$ concluded that due to the rearrangement of the soil particles during saturation, the soil matrix resulted in a significant reduction in the friction angle. Matric suction, a factor related to moisture content, is another principal factor affecting collapse deformation; the higher the matric suction, the higher the collapse potential for soil with specific density ${ }^{8}$. Shahriar, et al. ${ }^{18}$ conducted a comprehensive literature review on the effect of water level on the settlements of the foundations on granular material. They found that the settlement of the foundations due to water level rise depended on the stress level, soil friction angle, and soil relative density and was even more than twice as the settlement of the foundation on dry granular material.

Shape of the particles is important factor in the deformation characteristics of granular soils. Alonso ${ }^{19}$ showed that collapse settlements of embankment dams with alluvial gravels of rounded nature were very small especially when well-graded materials were found in the alluvial deposits. The particle shape may depend on the origin of the soil mass and its weathering process. Soil particles located close to their origin are generally angular, while those carried out by wind or water are usually rounded. Brink and van Rooy ${ }^{20}$ showed how a residual soil and transported soil with the same initial void ratio did not experience the same collapse settlement due to wetting. Shin and Santamarina ${ }^{21}$ conducted oedometer test on several mixtures of round Ottawa sand and angular blasting sand. They showed that oedometric compressibility of the soil mixture increased with angularity of the soil. This means that the angularity of the soil increases the potential settlement of the soil mass subjected to the normal load. Similar results were shown by Cabalar, et al. ${ }^{22}$ on four types of sands from Turkey and Cyprus; they found that material with higher roundness and sphericity in the particles showed lower compressibility.

The above review shows that little attention has been given to the effect of particle shape on the collapse deformation and stress reduction of gravel soils due to wetting. The prediction of the collapse settlement is of 
paramount importance in the alluvial deposits or man-made geo-structures subjected to change in the groundwater condition, such as embankment dams. In the majority of the previous studies on the effect of particle shape, different soils with different origins were investigated; however, in this study, a new method based on a standard laboratory technique is introduced to generate sub-rounded particles from angular particles so that particle shapes with the same mineral hardness are investigated.

This paper attempts to present the outcomes of a series of 40 direct shear tests on the stress reduction and collapse deformation of gravel soil with angular and sub-angular particle shapes. While the effect of relative density is investigated in this study, the main focus is particle shape, shear stress level and vertical stress on the collapse behaviour of the material. For all soil samples, index and physical properties were determined for soil description and sample preparation. Soil specimens with sub-angular particles and angular particles of the exact origin were prepared with the same particle size distribution (PSD) and the same density. Then the mediumscale direct shear test was used to evaluate deformation and strength characteristics of the soil specimens in three states: dry state, wet state, and dry-wet state.

\section{Soil material, sample preparation and method of testing}

\section{Soil material}

Soil samples in this study consisted of coarse aggregates obtained from the borrow resources of the ballast required for the railroad construction in the vicinity of Mianeh, a city in North West of Iran. The rock type was Trachytic tuff with an average dry and saturated compressive strength of 117 and $51 \mathrm{MPa}$, respectively. The crushed particles (Fig. 1a) were the results of a controlled explosion of the query. The photos of the soil particles were used to quantify the particle shape based on the procedure recommended by Muszynski and Vitton ${ }^{23}$ to determine Angularity (or roundness) (A) and Sphericity (S) ${ }^{24}$ of the particles. Angularity is the ratio of the average diameter of corners and edges to the diameter of the maximum inscribed sphere in a particle. Sphericity is the ratio of the diameter of a minimum sphere circumscribing a gravel particle to the maximum inscribed sphere in that particle. The authors evaluated both A and S based on 100 individual particle images with different sizes from 5 to $25 \mathrm{~mm}$. Quarter method of soil sampling was used to prepare 20 soil specimens from where the individual particles were selected. The average $\mathrm{A}$ and $\mathrm{S}$ in the material were 0.18 and 0.52 , respectively, so that the soil particles were classified as "angular" based on the most widely used comparator ${ }^{25,26}$ in Table 1. 


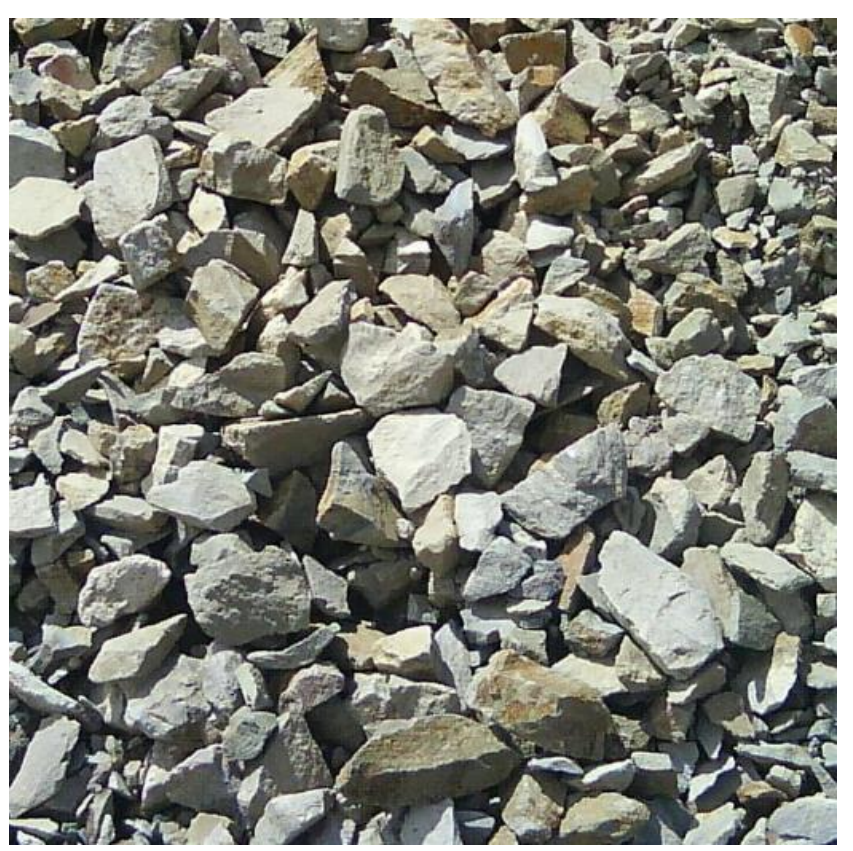

(a)

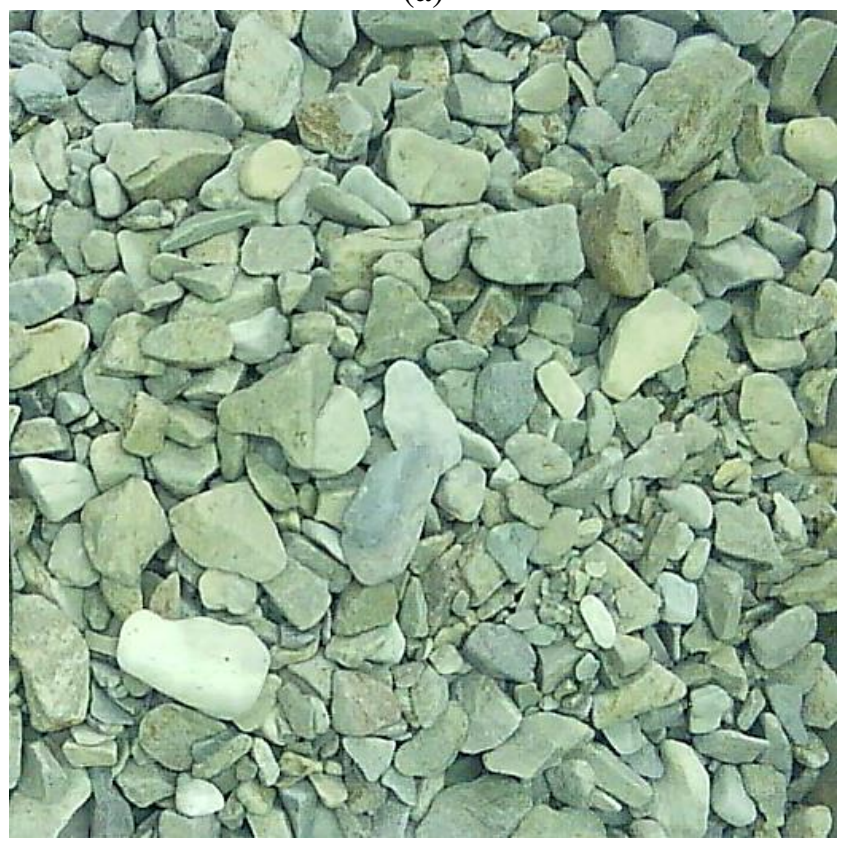

(b)

Figure 1. Soil particles. a angular particle shapes. $\mathbf{b}$ sub-angular particle shapes

Table 1. Classification of the soil particles based on their angularity ${ }^{26}$

\begin{tabular}{lcc}
\hline Angularity & $\begin{array}{c}\text { Class } \\
\text { limits }\end{array}$ & $\begin{array}{c}\text { Geometric } \\
\text { mid-point }\end{array}$ \\
\hline Very angular & $0.12-0.17$ & 0.14 \\
Angular & $0.17-0.25$ & 0.21 \\
Sub-angular & $0.25-0.35$ & 0.30 \\
Sub-rounded & $0.35-0.49$ & 0.41 \\
Rounded & $0.49-0.70$ & 0.59 \\
Well rounded & $0.70-1.00$ & 0.84 \\
\hline
\end{tabular}


The PSD curves of five selected samples are shown in Fig. 2. In order to conform to the requirements of the direct shear test suggested by ASTM D3080-11 ${ }^{27}$, the maximum size of the particles was set to $30 \mathrm{~mm}$ (less than $1 / 10$ of the shear box dimension). In this study, the mean particle size distribution of all samples was used to prepare soil specimens for the direct shear tests. The material is classified as well graded clean gravel (GW) based on the Unified Soil Classification System.

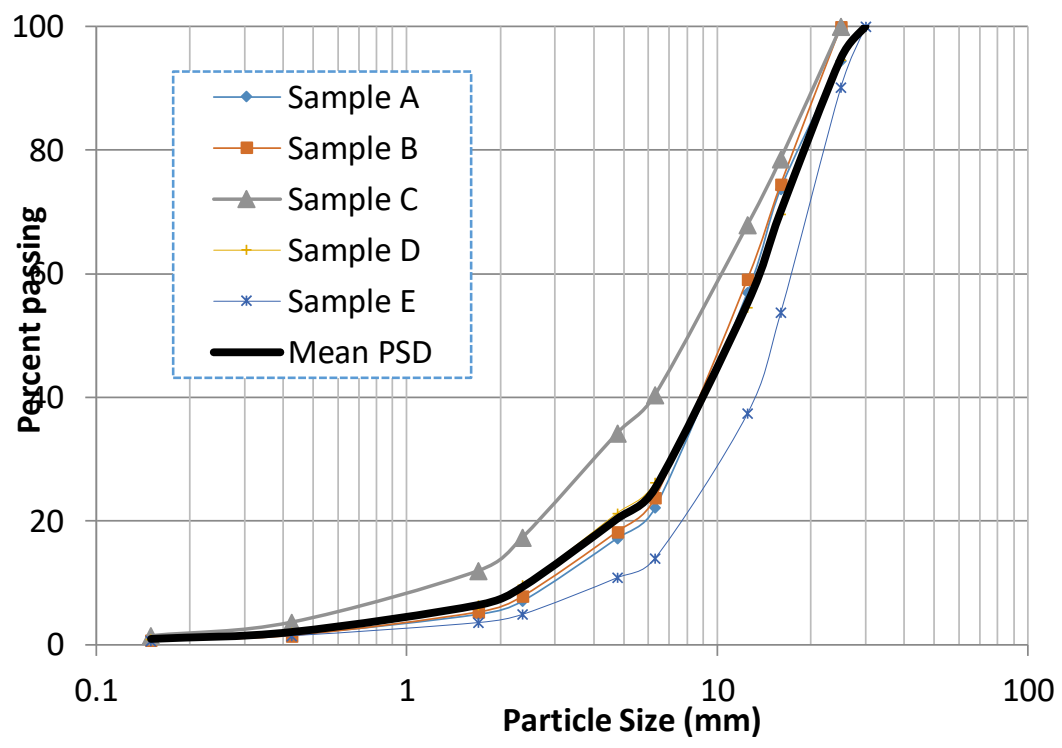

Figure 2. Particle size distribution of several samples and Mean PSD used for preparing shear box specimens

\section{Preparation of soils with sub-angular particles}

Because of the development process, weathering and the mechanism of soil deposits, it is not easy to find natural granular material with different particle shapes but of the same origin. For the preparation of the samples with sub-angular particle shapes, the Micro-Deval abrasion test ${ }^{28}$ was used (Fig. 3). This test is usually used to determine the abrasion loss of fine grain aggregate and its durability in a smooth drum, including water and small stainless steel balls.

In the standard method of conducting this test, 1500g coarse aggregate is used and immersed in tap water for a minimum of 1 hour. Then, 5000g stainless steel balls with $9.5 \mathrm{~mm}$ diameter are added to the test sample by using a Micro-Deval machine to rotate the jar at $100 \mathrm{rpm}$ for 2 hours. The soil sample is washed over a specified sieve (1.18 $\mathrm{mm}$ diameter for coarse aggregate), and the percentage is determined by comparing the oven-dried mass of the retained sample to the original total weight of the sample. After conducting this test on several soil samples from chosen angular soil material, the authors noticed that the remaining particles were sub-angular. Enormous contacts of the small steel balls to the soil particles during the test smoothened the corners of the 
particles. Soil material after the abrasion test with Micro-Deval is shown in Fig. 1b. Digital photos from the soil particles with different sizes were used to determine the angularity and sphericity of the particles. Individual particles were selected based on the same method presented in the previous section. The average A and S from 100 soil particles were 0.34 and 0.58 , respectively, which is an indication of sub-rounded particle shapes based on the roundness classification scheme presented in Table 1.

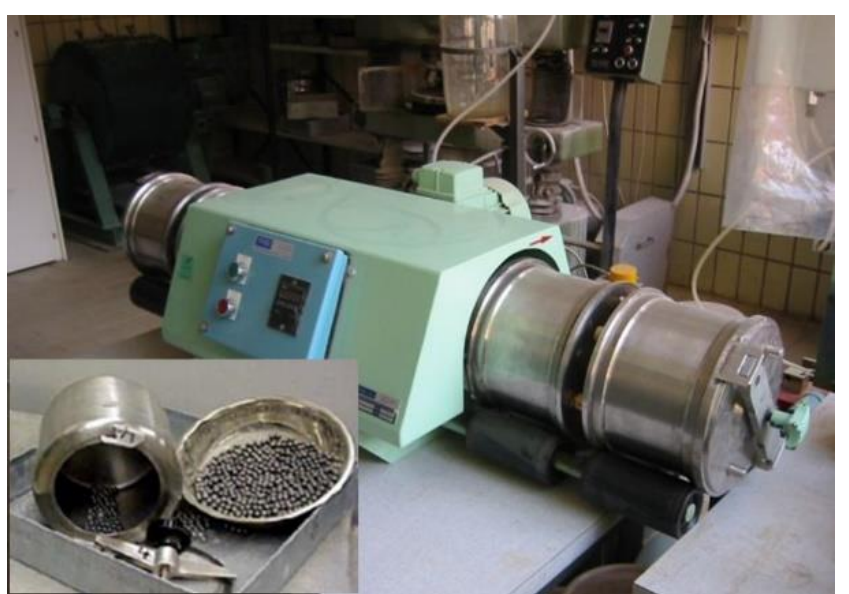

Figure 3. Micro-Deval Machine used in the study

The sub-angular particles from the Micro-Deval test were used to develop soil specimen with the same PSD curve as the angular particles. This was done by sieve analysis, separation of the particles to different sizes and mixing them with various fraction required for the mean PSD curve in Fig. 2.

\section{Shear box sample preparation}

Direct shear test specimens were prepared at the specific relative densities of $60 \%$ and $85 \%$. For instance, maximum and minimum dry density tests were conducted on both samples based on ASTM D4253 and ASTM D4254. The average parameters are presented in Table 2. Gs, $\gamma_{\mathrm{d}}, \gamma_{\mathrm{dmin}}$ and $\gamma_{\mathrm{dmax}}$ are specific gravity, dry density, minimum dry density and maximum dry density of the soil samples in this table.

Considering the minimum and maximum relative densities in table 2 and the specific relative densities, unit weight of final material $\left(\gamma_{\mathrm{d}}\right)$ were determined (Table 2). Based on these dry densities and the initial volume of the shear box, the amount of the material to be used in the shear box was obtained. The soil was compacted within six layers similar to the procedure recommended in ASTM D7181-11 29, as "tamping method" to reach the specified density. A square tamper with a cross section of $10 \mathrm{~cm} \times 10 \mathrm{~cm}$ was used to compact the material in each layer. Several attempts were made with trial and error so that the required materials fit in the shear box 
and reached the overall target density. The top layer was compacted with more caution to prepare a horizontal surface for the cap and vertical load. To investigate that the tamping method did not break the particles, the PSD curves of three soil specimens after the compaction were determined and compared with those before the compaction. The maximum breakage index (BI, introduced in section 4.3 of this paper) was less than $0.2 \%$, which showed very small change in PSD of the soil specimens after compaction.

Table 2. Density characteristics of angular and sub-angular material

\begin{tabular}{lccccc}
\hline Soil type & $\gamma_{\mathrm{dmax}}$ & $\gamma_{\mathrm{dmin}}$ & $\begin{array}{c}\gamma_{\mathrm{d}} \\
(\mathrm{Dr}=60 \%)\end{array}$ & $\begin{array}{c}\gamma_{\mathrm{d}} \\
(\mathrm{Dr}=85 \%)\end{array}$ & $\mathrm{G}_{\mathrm{s}}$ \\
\cline { 2 - 6 } & $\mathrm{kN} / \mathrm{m}^{3}$ & $\mathrm{kN} / \mathrm{m}^{3}$ & $\mathrm{kN} / \mathrm{m}^{3}$ & $\mathrm{kN} / \mathrm{m}^{3}$ & - \\
\hline Angular & 16.9 & 12.4 & 14.8 & 16 & 2.55 \\
Sub-angular & 18 & 14.4 & 16.4 & 17.3 & 2.55 \\
\hline
\end{tabular}

\section{Direct shear test apparatus and testing method}

Medium-scale direct shear test apparatus was used in this study. The dimension of the shear box was $30 \mathrm{~cm} \times 30$ $\mathrm{cm} \times 15 \mathrm{~cm}$. In this test, specimens were subjected to the specified level of normal stresses following a shear load with a constant displacement rate of $1 \mathrm{~mm} / \mathrm{min}$.

The direct shear test was conducted in three different states: dry condition, wet condition and dry-wet condition. In dry condition, the specimen was in a dry state while applying the vertical and shear load. In wet condition, the specimen was fully submerged during both stages of loading. In dry-wet condition, soil specimen was dry during applying vertical load and up to a specific shear stress level (SL) during shear loading. Then at this point, the specimen was submerged from the bottom of the shear box to the top in about 5 mins. The specimen was under this status for up to 25 mins without any interruption (this time constraint is to capture the maximum collapse of the specimen, which is illustrated in section 4.2). Finally, the shear load was continued to pass the peak shear stress in the wet state. It should be mentioned that creep deformation was not investigated in this study; however, 25 mins after saturation of the samples was relatively enough to compare the value of stress release and collapse deformation in different tests.

The laboratory study consists of 40 direct shear tests with the specimens subjected to three vertical pressures of 100,300 and $500 \mathrm{kPa}$. The experimental program is presented in Table 3. In this table, $\delta_{\mathrm{h}}$ and SL are shear 
displacement and shear stress level, respectively, right before wetting the specimens. SL is the percentage of the current shear stress $\left(\tau_{\mathrm{t}}\right)$ to the shear stress at failure point $\left(\tau_{\mathrm{f}}\right)$ in dry condition (Fig. 4a):

$$
S L=\frac{\tau_{t}}{\tau_{f}}
$$

SL in soil mass can vary from zero for horizontal layers to $100 \%$ in the slopes at the onset of failure. In this study SLs of $30 \%, 50 \%, 75 \%$ and $100 \%$ are considered for the tests to explore the collapse deformation of the material in a wide range of stress levels, observed in the body of embankment dams ${ }^{30}$ during construction and impoundment or in high road banks.

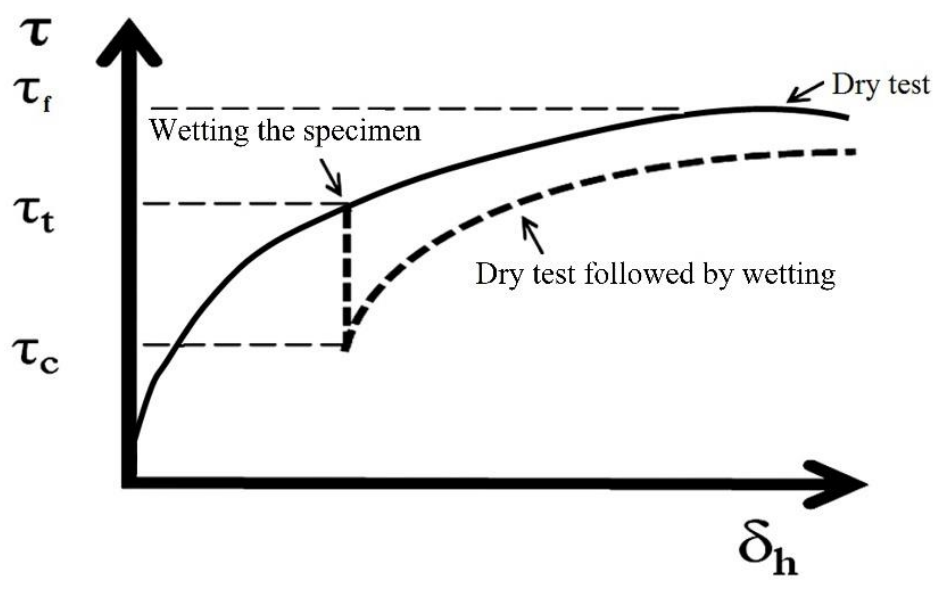

(a)

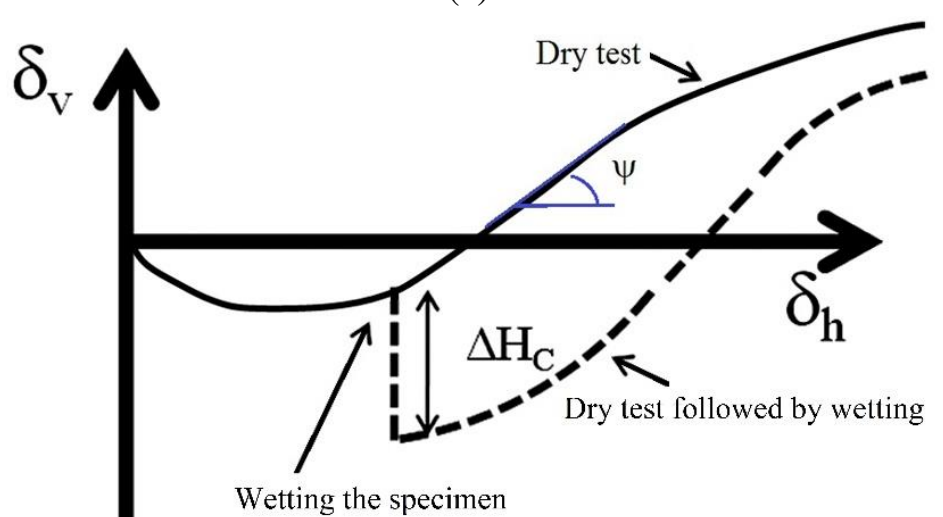

(b)

Figure 4. Typical curves for in dry test and dry followed by wetting. a shear stress-shear displacement. b vertical displacement-shear displacement 
Table 3. Experimental Plan

\begin{tabular}{|c|c|c|c|c|c|c|}
\hline $\begin{array}{l}\text { Purpose of the } \\
\text { Tests }\end{array}$ & $\begin{array}{c}\text { Shape of the } \\
\text { Particles }\end{array}$ & $\begin{array}{l}\text { Test } \\
\text { Type }\end{array}$ & $\begin{array}{c}\text { Relative } \\
\text { Density } \\
(\%)\end{array}$ & $\begin{array}{l}\text { Normal } \\
\text { Pressure } \\
(\mathrm{kPa})\end{array}$ & $\begin{array}{l}\text { Stress Level (SL) } \\
\text { during wetting (\%) }\end{array}$ & $\begin{array}{l}\text { Test } \\
\text { No. }\end{array}$ \\
\hline \multirow{12}{*}{$\begin{array}{c}\text { Effects of } \\
\text { Relative Density }\end{array}$} & \multirow{12}{*}{ Angular } & \multirow{12}{*}{ Dry-wet } & \multirow{3}{*}{85} & 100 & 0 & 1 \\
\hline & & & & 300 & 0 & 2 \\
\hline & & & & 500 & 0 & 3 \\
\hline & & & \multirow{3}{*}{60} & 100 & 0 & 4 \\
\hline & & & & 300 & 0 & 5 \\
\hline & & & & 500 & 0 & 6 \\
\hline & & & \multirow{3}{*}{85} & 100 & 50 & 7 \\
\hline & & & & 300 & 50 & 8 \\
\hline & & & & 500 & 50 & 9 \\
\hline & & & \multirow{3}{*}{60} & 100 & 50 & 10 \\
\hline & & & & 300 & 50 & 11 \\
\hline & & & & 500 & 50 & 12 \\
\hline \multirow{28}{*}{$\begin{array}{l}\text { Effects of normal } \\
\text { pressure and } \\
\text { stress level }\end{array}$} & \multirow{14}{*}{ Angular } & \multirow{3}{*}{ Dry } & \multirow{3}{*}{85} & 100 & - & 13 \\
\hline & & & & 300 & - & 14 \\
\hline & & & & 500 & - & 15 \\
\hline & & Wet & 85 & 300 & - & 16 \\
\hline & & \multirow{9}{*}{ Dry-Wet } & \multirow{10}{*}{85} & 100 & $72\left(\delta_{\mathrm{h}}=5 \mathrm{~mm}\right)$ & 17 \\
\hline & & & & 300 & $46\left(\delta_{\mathrm{h}}=5 \mathrm{~mm}\right)$ & 18 \\
\hline & & & & 500 & $42\left(\delta_{\mathrm{h}}=5 \mathrm{~mm}\right)$ & 19 \\
\hline & & & & 300 & 30 & 20 \\
\hline & & & & 300 & 50 & 21 \\
\hline & & & & 300 & 75 & 22 \\
\hline & & & & 300 & 100 & 23 \\
\hline & & & & 500 & 50 & 24 \\
\hline & & & & 500 & 75 & 25 \\
\hline & & & & 500 & 100 & 26 \\
\hline & \multirow{14}{*}{ Sub-Angular } & \multirow{3}{*}{ Dry } & \multirow{3}{*}{85} & 100 & - & 27 \\
\hline & & & & 300 & - & 28 \\
\hline & & & & 500 & - & 29 \\
\hline & & Wet & 85 & 300 & - & 30 \\
\hline & & \multirow{10}{*}{ Dry-Wet } & \multirow{10}{*}{85} & 100 & $68\left(\delta_{\mathrm{h}}=5 \mathrm{~mm}\right)$ & 31 \\
\hline & & & & 300 & $54\left(\delta_{\mathrm{h}}=5 \mathrm{~mm}\right)$ & 32 \\
\hline & & & & 500 & $47\left(\delta_{\mathrm{h}}=5 \mathrm{~mm}\right)$ & 33 \\
\hline & & & & 300 & 30 & 34 \\
\hline & & & & 300 & 50 & 35 \\
\hline & & & & 300 & 75 & 36 \\
\hline & & & & 300 & 100 & 37 \\
\hline & & & & 500 & 50 & 38 \\
\hline & & & & 500 & 75 & 39 \\
\hline & & & & 500 & 100 & 40 \\
\hline
\end{tabular}




\section{Parameters for comparison}

Fig. 4 shows the typical shear stress -shear displacement and vertical displacement-shear displacement of the direct shear tests in dry and dry-wet condition. In the latter test, the shear force was applied to the dry samples reaching shear stress of $\tau_{t}$, and then the soil specimen was inundated without shearing for 25 mins. After this time, the shear load was continued to pass the peak shear stress. During inundation of the samples, collapse behaviour results in a drop in the shear stress to $\tau_{\mathrm{c}}$ and sudden vertical displacement called collapse settlement $(\Delta \mathrm{Hc}$ in Fig $4 \mathrm{~b})$. Following parameters are used in this study:

$\tau_{t c}=\tau_{t}-\tau_{c}$

$C_{s r}=\tau_{c} / \tau_{t}$

where $\tau_{t c}$ and $C_{s r}$ are stress relaxation and coefficient of stress recovery, respectively. Equation 3 is similar to the equation suggested by Justo ${ }^{31}$ in the oedometer test. He introduced parameter "a" as the relaxation coefficient with the following relation:

$\mathrm{a}={ }^{\tau_{t c}} / \tau_{t}=1-C_{s r}$

\section{Results and discussions}

\section{Collapse settlement, relative density and normal stress level}

The purpose of these initial tests was first to confirm the results of the tests with the similar studies by previous researchers and second, to determine the necessary time for the collapse settlement, which is required in the direct shear tests. The effect of relative density on the collapse settlement of angular material was investigated in two series of tests. At the first series, specimens under specific vertical loads (without shearing) were submerged, and vertical deformation was monitored. At the second series of tests, the inundation of the samples occurred after vertical load and at a specific shear stress level.

For the first series, six dry samples were prepared in the shear box with relative densities of $60 \%$ and $85 \%$ and subjected to the vertical loads of 100, 300 and $500 \mathrm{kPa}$ (Table 3, No.1-6). After reaching the final settlement in the dry state, the samples were submerged, and collapse settlements were measured, presented in Fig. 5a. As can be seen, after 15 mins all the samples reach their final settlement. This figure shows that in all vertical stresses, the collapse settlement of the samples decreases with an increase in the relative density. Also, the higher the 
vertical load, the higher the collapse settlement in the samples. These results confirm the results of the tests conducted by other researchers ${ }^{16,32,33}$.

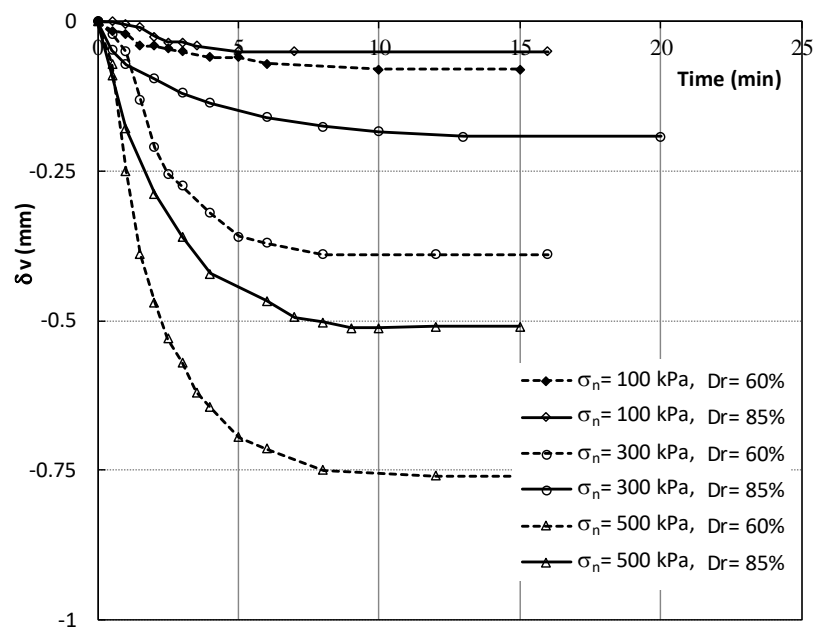

(a)

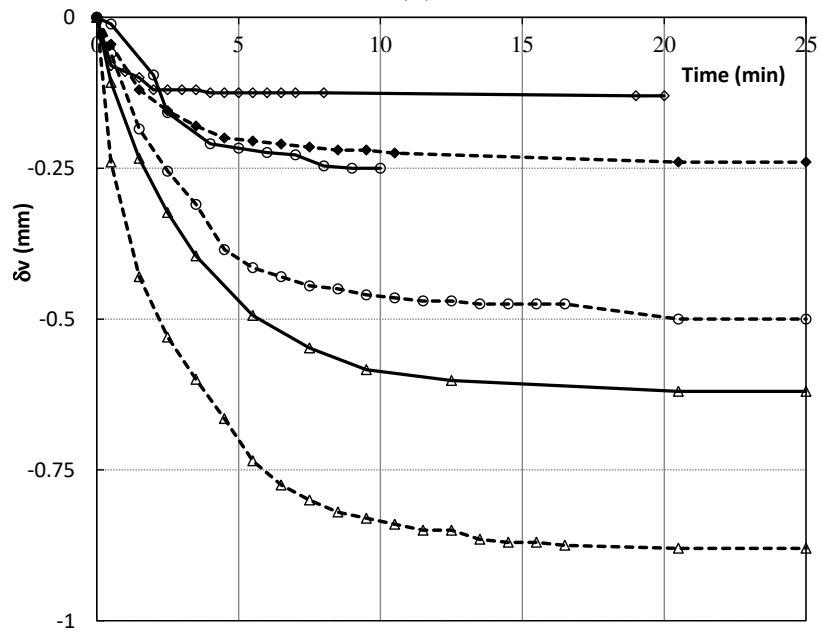

(b)

Figure 5. Effect of relative density and normal stress on the collapse settlement. a SL=0. b SL=50\%

At the second series of the tests, six dry samples were loaded under the same vertical pressures, but the samples were submerged during shear displacement at the shear stress level of 50\% (Table 3, No.7-12). The changes of collapse settlement of the samples with time are shown in Fig. 5b. Variation of collapse settlement with density and vertical pressure is similar to that of previous tests but with higher intensity. It means that collapse settlement increases with an increase in the shear stress level in all vertical stress and relative densities. These results confirm the finding by Tabibnejad, et al. ${ }^{33}$ on rockfills and Hasanzadehshooiili, et al. ${ }^{34}$ on coarse and clean gravel. 
The above tests showed that the collapse settlement became steady and constant about 25 mins after wetting of the samples, while no shear displacement applied. Therefore, 25 mins were used for the collapse settlement before shearing applied.

\section{Effect of particle shape on collapse settlement and stress reduction}

In total, 28 direct shear tests were conducted with vertical stresses of 100,300 and $500 \mathrm{kPa}$ and the relative density of $85 \%$ at different shear stress levels (Table 3, No. 13-40). This high value of relative density was used because, in most large geo-structures (e.g. embankment dams more than $15 \mathrm{~m}$ height), the relative density of $85 \%$ is suggested as a desired average density for quality assurance of the compacted shell ${ }^{35}$.

Samples were submerged in two conditions: in specific shear displacement or specific shear stress levels. In test No. 17, 18, 19, 31, 32 and 33 (Table 3), the inundation was made when the samples reached the horizontal displacement of $5 \mathrm{~mm}$. This shear displacement corresponded to a slight change in shear stress level (from $42 \%$ to $72 \%$ at Table 3). The rest of the tests were conducted in the stress level ranges from $30 \%$ to $100 \%$ to study collapse behaviour and shear relaxation of the soil material in a wide range of shear stress levels.

\section{Collapse settlement and stress reduction due to inundation in a constant shear displacement}

For the first series of the tests, Fig. 6 and Fig. 7 show the results of the direct shear tests on specimens with angular particle shapes and sub-angular particle shapes, respectively. In these figures, dry tests and dry-wet tests are shown with solid and dashed curves, respectively. Figs. 6a and 7a show that shear strengths of dry samples are higher than those from dry-wet tests at the same vertical stresses. It is because samples in the latter tests were inundated before they reached their peak strength. The stress relaxation occurs in all dry-wet tests in both specimens with angular and sub-angular particles. It can be seen that the stress relaxation increases with vertical stress in both types of specimens, which is in good agreement with the trends observed in other coarse grain material such as rockfill material and sandy soils ${ }^{36,37}$.

Figs. $6 \mathrm{~b}$ and $7 \mathrm{~b}$ show the deformation behaviour of the both types of samples subjected to shearing. Compared with dry-wet samples, dry samples show higher vertical displacement during shearing in both angular and supangular particles because of their higher shear strength. Also, it can be seen that an increase in the vertical stress corresponds to a decrease in the dilatancy behaviour in all these tests; the higher vertical pressure, the higher degradation in the corners of the particles due to stress concentration ${ }^{36}$. These figures also show that the collapse settlement $\left(\Delta \mathrm{H}_{\mathrm{c}}\right)$ in both types of samples increases with the vertical stress. This is in agreement with the study by Naderian and Williams ${ }^{32}$ and Heshmati, et al. ${ }^{36}$ on other types of granular material. 
Another result from the above comparison is that stress relaxation and collapse settlement in specimens with angular particle shapes are higher than those in specimens with sub-angular particle shapes at each level of vertical stress. This is very similar to the study by Shin and Santamarina ${ }^{21}$ on particle angularity and the compressibility of granular mixtures. They showed that with increasing the fraction of angular particles in the oedometer test, the compression index of the samples increased, resulting in more settlement due to the vertical load.

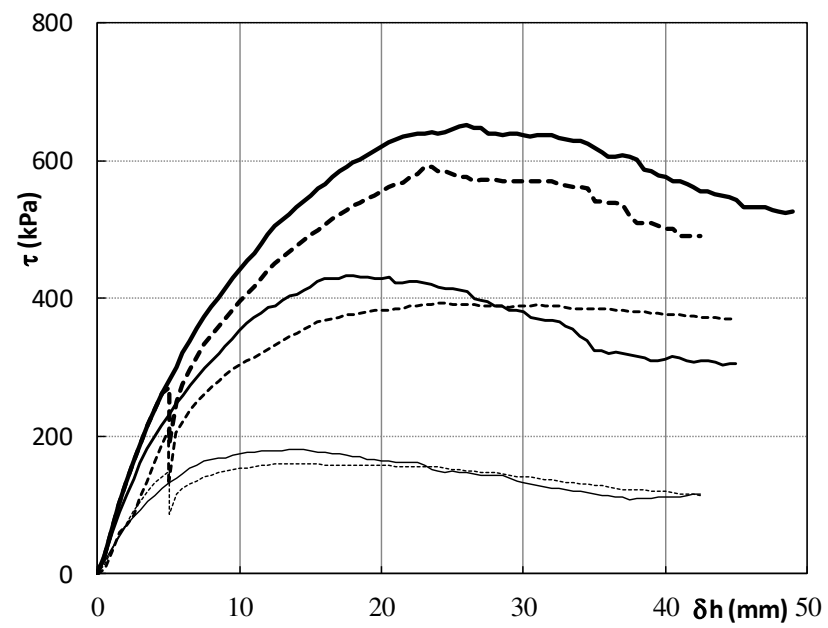

(a)

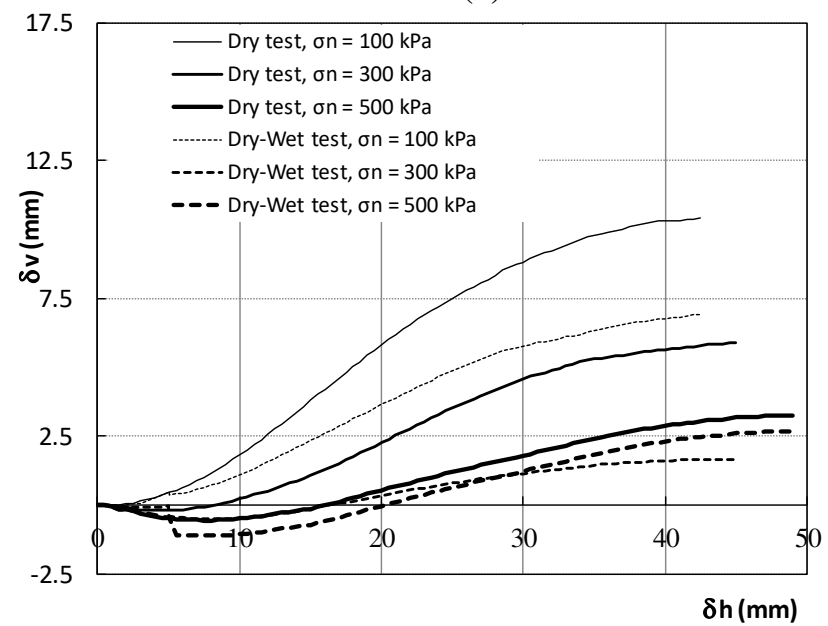

(b)

Figure 6. Direct shear test results on specimens with angular particle shapes $(\mathrm{Dr}=85 \%)$. a shear stress-shear displacement. b vertical displacement-shear displacement 


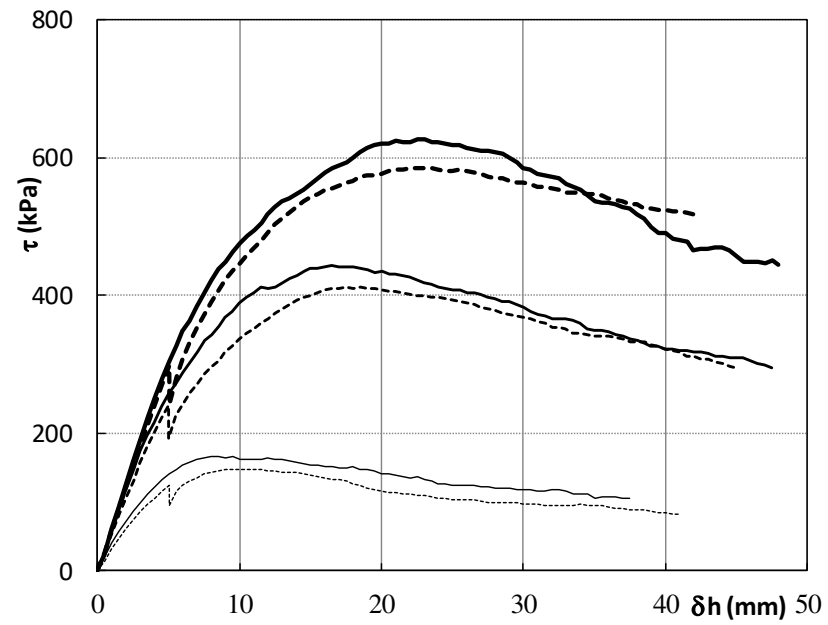

(a)

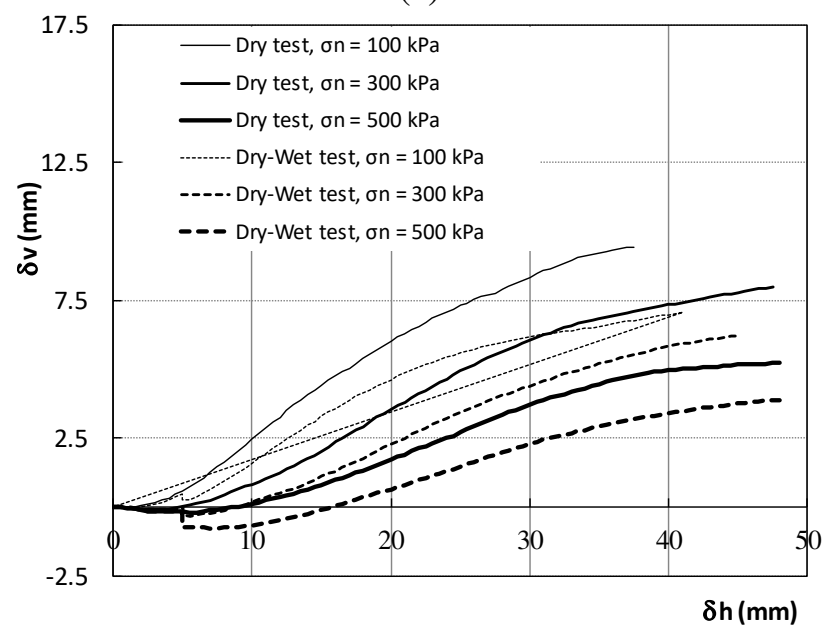

(b)

Figure 7. Direct shear test results on specimens with sub-angular particle shapes $(\mathrm{Dr}=85 \%)$. a shear stress-shear displacement. b vertical displacement-shear displacement

\section{Collapse settlement and stress reduction due to inundation in a broader shear stress level}

Inundation of the samples in the Dry-Wet tests in the previous section occurred under a specific horizontal displacement of $5 \mathrm{~mm}$, which corresponds to the narrow range in the shear stress levels. In order to study the collapse behaviour of angular and sub-angular particles in a higher range of shear stress level, 14 direct shear tests were conducted on initially dry samples with a relative density of $85 \%$, vertical stresses of 300 and $500 \mathrm{kPa}$ and SLs of 30, 50, 75 and $100 \%$. The specification of these tests are shown in the experimental plan at Table 3 (No. 20-26 and No. 34-40). Based on the results of the shear tests, variation of the stress relaxation, collapse settlement and coefficient of stress recovery to the shear stress levels for both vertical stress of 300 and $500 \mathrm{kPa}$ are shown in Fig. 8. 


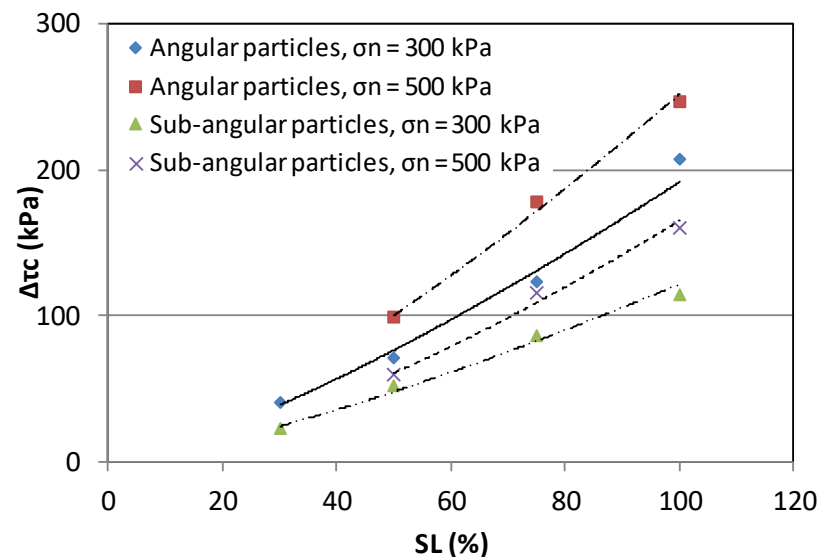

(a)

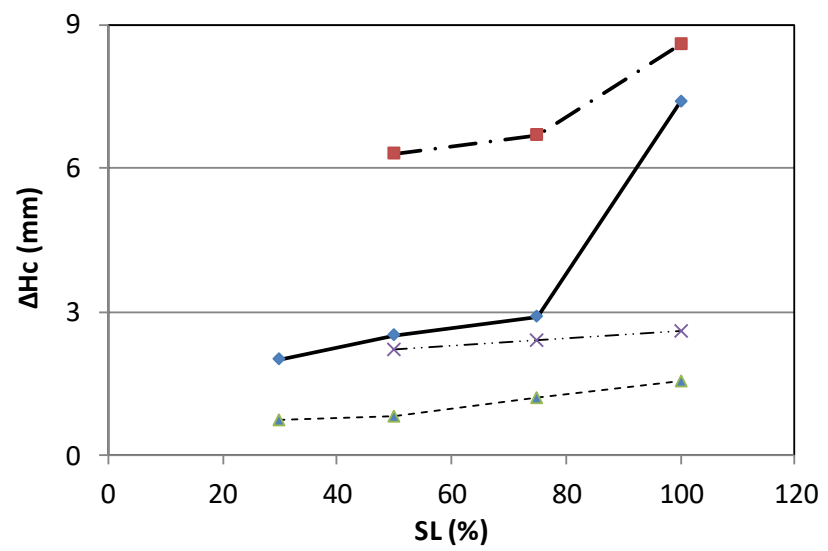

(b)

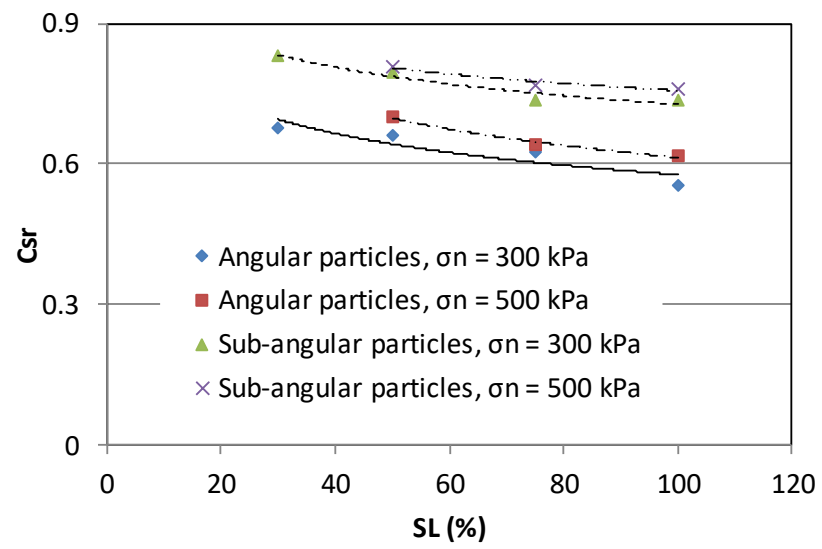

(c)

Figure 8. Effect of particle shape on a stress relaxation, $\mathbf{b}$ collapse settlement and $\mathbf{c}$ Coefficient of stress recovery

Fig. 8a shows that for both sub-angular and angular materials with increasing shear stress level and normal pressure, stress relaxation increases. Also, it is evident that material with sub-angular particles in both vertical stresses shows less stress relaxation than angular particles. It means that dry gravel soils with angular particles are more prone to stress relaxation due to saturation. This reality is associated with more collapse settlement in angular soils, which is illustrated in Fig. 8b. This figure shows changes of collapse settlement with shear stress level for both angular and sub-angular particles. In both vertical stresses, samples with sub-angular particle 
shapes show less deformation than those with angular particles. The samples with angular particles are three times more likely to settle than the samples with sub-angular particles. This result is in accord with the study by Alonso ${ }^{19}$ indicating that collapse settlements of dams made of alluvial gravels with the rounded nature of the particles were very small. The collapse settlement and stress relaxation are higher in higher shear stresses, probably because the stress states in the specimens are closer to the failure line. Higher vertical stress intensifies this phenomenon because there are higher inter-particle stresses.

In Fig. 9c, changes of the coefficient of stress recovery are shown. This figure shows that with increasing shear stress level, $\mathrm{C}_{\mathrm{sr}}$ decreases in all types of samples, but this value in sub-angular particles is higher than that of angular particles, which shows less collapsibility in the samples with sub-angular particles.

In this study, both types of samples with angular and sub-angular particles have the same relative density and the same origin, but the material with sub-angular particles are denser than that of the angular particle (Table 2); for example, with a relative density of $85 \%$, weight density of the specimen with subangular and angular particles are $1.73 \mathrm{~g} / \mathrm{cm}^{3}$ and $1.6 \mathrm{~g} / \mathrm{cm}^{3}$, respectively. This is because the minimum and maximum densities of the soils with sub-angular particles $\left(1.44\right.$ and $\left.1.8 \mathrm{~g} / \mathrm{cm}^{3}\right)$ are higher than those of the soil with angular particles $(1.24$ and $1.69 \mathrm{~g} / \mathrm{cm}^{3}$ ). Both relative density and soil density should be considered in the compaction of the material.

Another reason for the higher value of collapse settlement in the soil with angular particles is the stress concentration in the corners of the particles in contact with other particles, which results in more rearrangement and particle breakage due to wetting. In soils with angular gravels, particle breakage is of paramount importance on the collapse settlement due to wetting, which is described quantitatively in the following section.

\section{Particle breakage}

When the stress applied to the soil particle is higher than its strength, the particle may break. As it was mentioned in the introduction, different factors are effective on particle breakage. Among them, stress level, particle shape and water presence are the main focus in this section. The method of sample preparation, applied loads, and the saturation of the initially dry samples can cause the particles to break during shear test, resulting in different PSD at the end of the tests. The intensity of the breakage can be evaluated by comparison of the PSD before and after the test. For instance, the method presented by Indraratna, et al. ${ }^{38}$ for the ballast material in the railways is used in this section to identify the breakage of the samples quantitatively. In this study, the initial PSD curves of all samples are the same and are shown in Fig. 2. For the final PSD curve, sieve analyses 
were conducted on the soil material after the shear test. Considering Fig. 9, the breakage index is defined as follow:

$B I=A /(A+B)$

where $\mathrm{A}=$ area between initial PSD and final PSD and $\mathrm{B}=$ Area between the final PSD and arbitrary boundary of maximum breakage. This boundary is a straight line with two specific sieve size for zero and $100 \%$ passing. In this study, for zero passing, the smallest sieve size of $0.15 \mathrm{~mm}$ was used, and for $100 \%$ passing, $95 \%$ of the largest sieve size $(23.75 \mathrm{~mm})$ was used to define the arbitrary boundary. With the above definition, the breakage index is between zero (no breakage) and 100\% (maximum breakage).

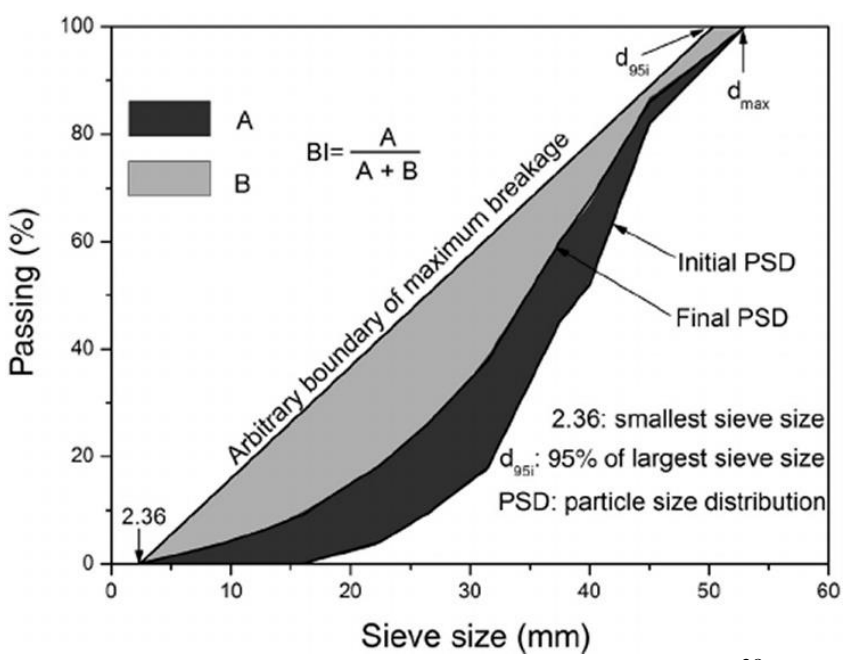

Figure 9. Definition of particle breakage index ${ }^{38}$

By comparing the PSD curves before and after the direct shear tests, the breakage index in 6 soil specimens with sub-angular particle shape and 4 soil specimens with angular particle shape was determined in different normal pressures. Fig. 10 shows PSD curves for a soil specimen with angular particle shapes. The PSD curve of the soil specimen moved to the left side after the shear test due to particle breakage, resulting in a breakage index of $2.8 \%$ based on the above definition. 


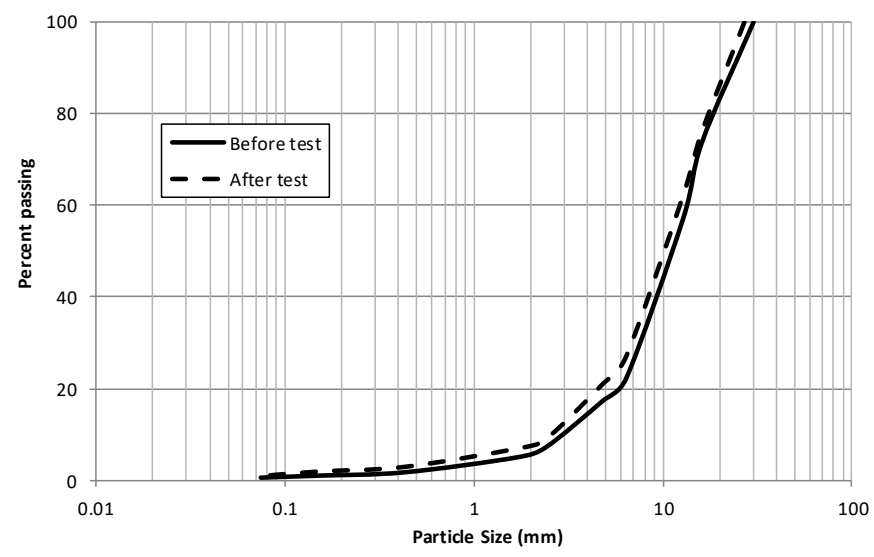

Figure 10. PSD curves before and after the direct shear test on a soil specimen with angular particles (Dry-Wet test, $\sigma_{\mathrm{n}}=300 \mathrm{kN} / \mathrm{m}^{2}$ )

Changes of the breakage index with normal pressure in specimens with angular and sub-angular particle shapes are presented in Fig. 11. As can be seen breakage index increases linearly with the normal pressure, which confirms the observation by other researchers ${ }^{4,36}$. Fig. 6 shows that soil specimens with angular particles are more prone to particle breakage during shearing, either in the dry or wet state. This might be associated with higher degradation in the corner of the angular particles due to stress concentration. In both soils with angular and sub-angular particles, the breakage index in dry samples is lower than that in the dry-wet test. In dry-wet tests, soil samples were initially dry and then submerged, in which all the factors (sample preparation, loading and wetting) caused the material to break, while in dry tests, only sample preparation and loading were the main reasons for breakage of the samples. It can be seen that inundation of the samples has more impact on the particle breakage in angular particles than sub-angular particles; e.g. at the vertical stress of $500 \mathrm{kPa}, \mathrm{BI}$ increases from 2.4 to 3.48 in the sample with angular particles (45\% increase in $\mathrm{BI}$ ) in comparison with the increase from 1.5 to 1.7 in the sample with sub-angular particles (only $13 \%$ increase in BI). 


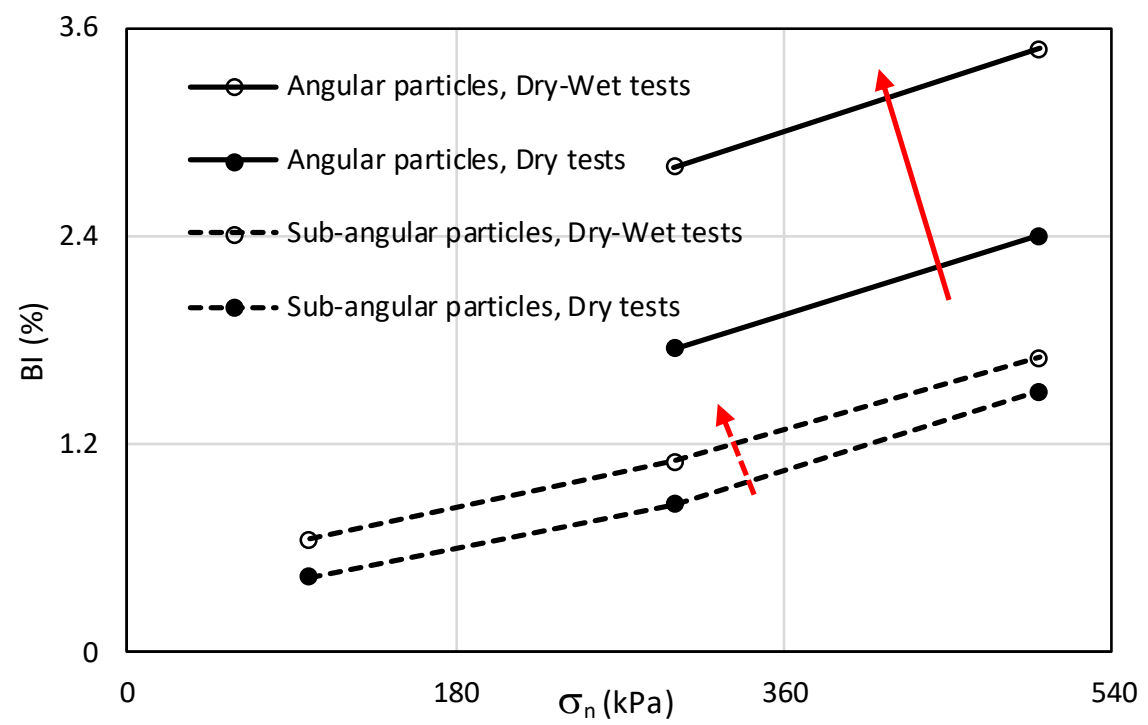

Figure 11. Variation of particle breakage index with normal pressure

\section{Conclusion}

This study was designed to investigate the effect of particle shape on the stress reduction and collapse deformation of coarse grain soils due to wetting. A new method was introduced using the current standard procedure for the Micro-Deval test to prepare samples with sub-angular particles from the samples with angular particle shapes. Therefore, the effect of different particle shapes with the same parental rock type, the same PSD curve and the same relative density was studied. It was shown that the shear stress relaxation and collapse settlement in the samples with angular particles were higher than those in the samples with sub-angular particles, the amount of which increased with vertical stress and shear stress level. The main reason for this phenomenon would be the higher particle breakage in the soil with angular particles. The quantitative analysis of the breakage of the soil particles after the shear tests showed that the breakage index of the samples with angular-particle shape was higher than that of sub-angular particle shape. Particle breakage in all samples increased with normal stress and wetting the samples. The effect of wetting on the particle breakage of soils with angular particle shapes was significantly higher than that of soils with sub-angular particles.

\section{References}

1 Ali, M. Identifying and Analyzing Problematic Soils. Geotech Geol Eng 29, 343-350, doi:10.1007/s10706-010-9380-y (2011).

2 Zhao, J. et al. Experimental study of reservoir bank collapse in gravel soil under different slope gradients and water levels. Natural hazards (Dordrecht) 102, 249-273, doi:10.1007/s11069-02003922-z (2020). 
3 Barden, L., McGown, A. \& Collins, K. The collapse mechanism in partly saturated soil. Eng Geol 7, 49-60 (1973).

4 Asadzadeh, M. \& Soroush, A. Direct shear testing on a rock fill material. Arab J Sci Eng 34, 379396 (2009).

5 Nouaouria, M. S., Guenfoud, M. \& Lafifi, B. Engineering properties of loess in Algeria. Eng Geol 99, 85-89, doi:10.1016/j.enggeo.2008.01.013 (2008).

6 Alawaji, H. A. Shear induced collapse settlement of arid soils. Geotech Geol Eng 19, 1-19, doi:10.1023/A:1012223622250 (2001).

7 Alonso, E. \& Cardoso, R. Behavior of materials for earth and rockfill dams: Perspective from unsaturated soil mechanics. Selected Publications from Chinese Universities 4, 1-39, doi:10.1007/s11709-010-0013-6 (2010).

8 Rabbi, A. T. M. Z., Cameron, D. A. \& Rahman, M. M. in Unsaturated Soils: Research \& Applications (ed Russell \& Khoshghalb Khalili) 129-135 (Taylor \& Francis Group, London, 2014).

9 Hunter, G. J. The Pre- and Post-failure Deformation Behaviour of Soil Slopes, University of New South Wales, Australia, (2003).

10 Escuder, I., Andreu, J. \& Rechea, M. An analysis of stress-strain behaviour and wetting effects on quarried rock shells. Canadian Geotechnical Journal 42, 51-60, doi:10.1139/T04-071 (2005).

11 Soroush, A. \& Aghaei Araei, A. in 73rd Annual Meeting of Icold (Tehran, Iran, 2005).

12 Lade, P. V., Yamamuro, J. A. \& Bopp, P. A. Significance of Particle Crushing in Granular Materials. J Geotech Geoenv Eng 122, 309-316, doi:10.1061/(ASCE)0733-9410(1996)122:4(309) (1996).

13 Soleimani, S., Jiao, P., Rajaei, S. \& Forsati, R. A new approach for prediction of collapse settlement of sandy gravel soils. Engineering with Computers 34, 15-24, doi:10.1007/s00366-0170517-y (2018).

14 Margherita, Z., Laura, E., Bartolomeo, M. \& Roberto, S. Collapsibility of metastable sand by nonconventional oedometer tests. Granular matter 21, 1-11, doi:10.1007/s10035-018-0854-6 (2018).

15 Rodrigues, R. A. \& de Lollo, J. A. Influence of domestic sewage leakage on the collapse of tropical soils. Bull Eng Geol Environ 66, 215-223, doi:10.1007/s10064-006-0065-y (2006).

16 Nobari, E. S. \& Duncan, J. M. Effect of reservoir filling on stresses and movements in earth and rockfill dams. Report No. TE-72-1, (University of California, 1972).

17 Silvani, C., Bonelli, S., Philippe, P. \& Desoyer, T. Buoyancy and local friction effects on rockfill settlements: A discrete modelling. Comput Math Appl 55, 208-217, doi:10.1016/j.camwa.2007.04.011 (2008).

18 Shahriar, M. A. N., Das, B. M. \& Sivakugan, N. Developments in quantifying the effect of water table rise on additional settlements of shallow foundations resting on granular soils. International Journal of Geotechnical Engineering 9, 67-78, doi:10.1179/1939787914Y.0000000077 (2015).

19 Alonso, E. Fracture mechanics and rockfill dams. Soil Rock 37, 3-35 (2014).

20 Brink, G. \& van Rooy, J. L. The influence of the geological origin on soil volume change through collapse settlement. J Afr Earth Sci 101, 113-118, doi:10.1016/j.jafrearsci.2014.09.007 (2015).

21 Shin, H. \& Santamarina, J. C. Role of particle angularity on the mechanical behavior of granular mixtures. J Geotech Geoenv Eng 139, doi:10.1061/(ASCE)GT.1943-5606.0000768 (2013).

22 Cabalar, A. F., Dulundu, K. \& Tuncay, K. Strength of various sands in triaxial and cyclic direct shear tests. Eng Geol 156, 92-102, doi:10.1016/j.enggeo.2013.01.011 (2013).

23 Muszynski, M. R. \& Vitton, S. J. particle shape estimates of uniform sands: Visual and automated methods comparison. Journal of Materials in Civil Engineering 24, 194-206, doi:10.1061/(ASCE)MT.1943-5533.0000351 (2012).

24 Wadell, H. Volume, shape, and roundness of rock particles. J Geol 40, 443-451 (1932).

25 Blott, S. J. \& Pye, K. Particle shape: a review and new methods of characterization and classification. Sedimentol 55, 31-63, doi:10.1111/j.1365-3091.2007.00892.x (2008).

26 Powers, M. C. A new roundness scale for sedimentary particles. J of Sediment Pet 23, 117-119 (1953).

27 ASTM D3080-11. (ASTM International, West Conshohocken, PA, 2011).

28 ASTM D7428-17. (ASTM International, West Conshohocken, PA, 2017).

29 ASTM D7181-11. (ASTM International, West Conshohocken, PA, 2011). 
30 Mahinroosta, R., Alizadeh, A. \& Gatmiri, B. Simulation of collapse settlement of first filling in a high rockfill dam. Eng Geol 187, 32-44, doi:10.1016/j.enggeo.2014.12.013 (2015).

31 Justo, J. L. in Advances in Rockfill Structures (ed E. Maranha das Neves) 97-152 (Kluwer Academic Publishers, 1991).

32 Naderian, A. R. \& Williams, D. J. Bearing capacity of open-cut coal mines backfill materials. Trans. Inst. Min. Metall 106, A30-A34 (1997).

33 Tabibnejad, A., Heshmati, A., Salehzadeh, H. \& Tabatabaei, S. H. Effect of gradation curve and dry density on collapse deformation behavior of a rockfill material. KSCE J Civ Eng 19, 631-640, doi:10.1007/s12205-013-0682-5 (2014).

34 Hasanzadehshooiili, H., Mahinroosta, R., Lakirouhani, A. \& Oshtaghi, V. Using artificial neural network (ANN) in prediction of collapse settlements of sandy gravels. Arab J Geosci 7, 23032314, doi:10.1007/s12517-013-0858-9 (2014).

35 USBR. 273 (US Department of the Interior, Bureau of Reclamation, 1998).

36 Heshmati, A., Tabibnejad, A., Salehzadeh, H. \& Tabatabaei, S. H. Effect of stress conditions on collapse deformation behavior of a rockfill material. KSCE J Civ Eng 19, 1637-1646, doi:10.1007/s12205-014-1175-x (2014).

37 Mahinroosta, R. \& Poorjafar, A. Effect of stress state and particle-size distribution on the stress reduction of sandy soils during saturation. Constr Build Mater 150, 1-13, doi:10.1016/j.conbuildmat.2017.05.177 (2017).

38 Indraratna, B., Lackenby, J. \& Christie, D. Effect of confining pressure on the degradation of ballast under cyclic loading. Geotech 55, 325-328, doi:10.1680/geot.2005.55.4.325 (2005).

\section{Acknowledgment}

We acknowledge financial support provided by Charles Sturt University. We also greatly appreciate the valuable suggestions given by Dr J. Moradloo and the support by Mr M. Shahbazi for the laboratory works.

\section{Author contributions}

R.M's contributions are: Conceptualisation, designing the laboratory works and methodology, investigation, writing the original draft and finalising the paper. V.O.'s contributions are: conducting the laboratory tests, investigation, reviewing and revising the paper.

\section{Competing interests}

The authors declare no competing interests. 


\section{Figures}

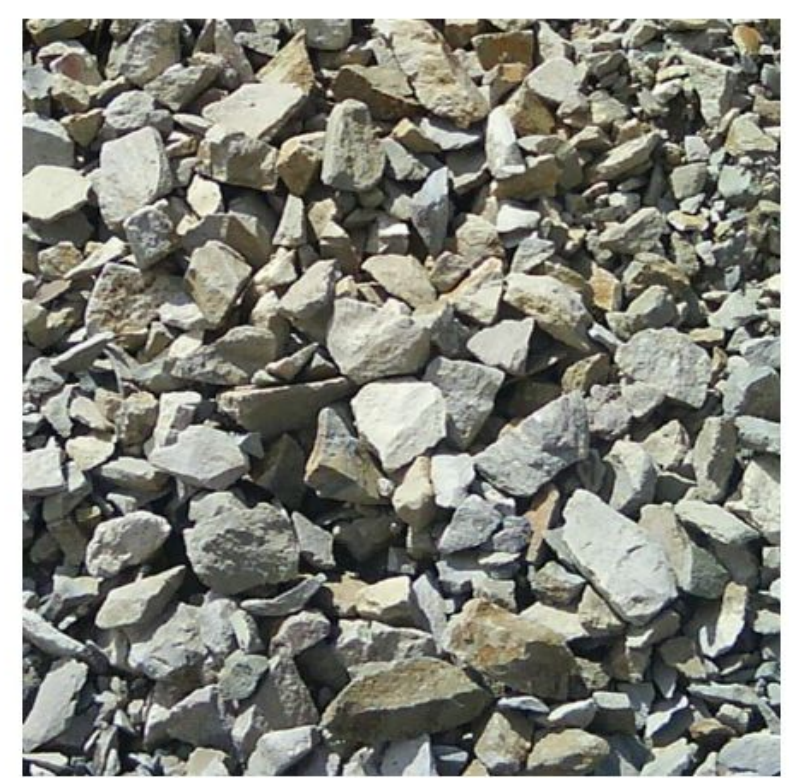

(a)

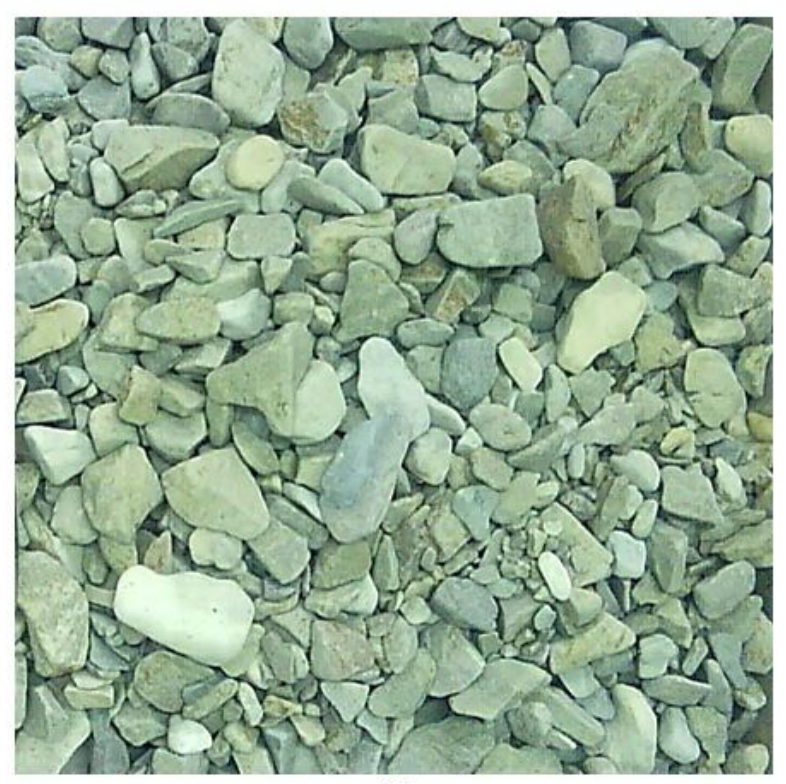

(b)

Figure 1

Soil particles. a angular particle shapes. b sub-angular particle shapes 


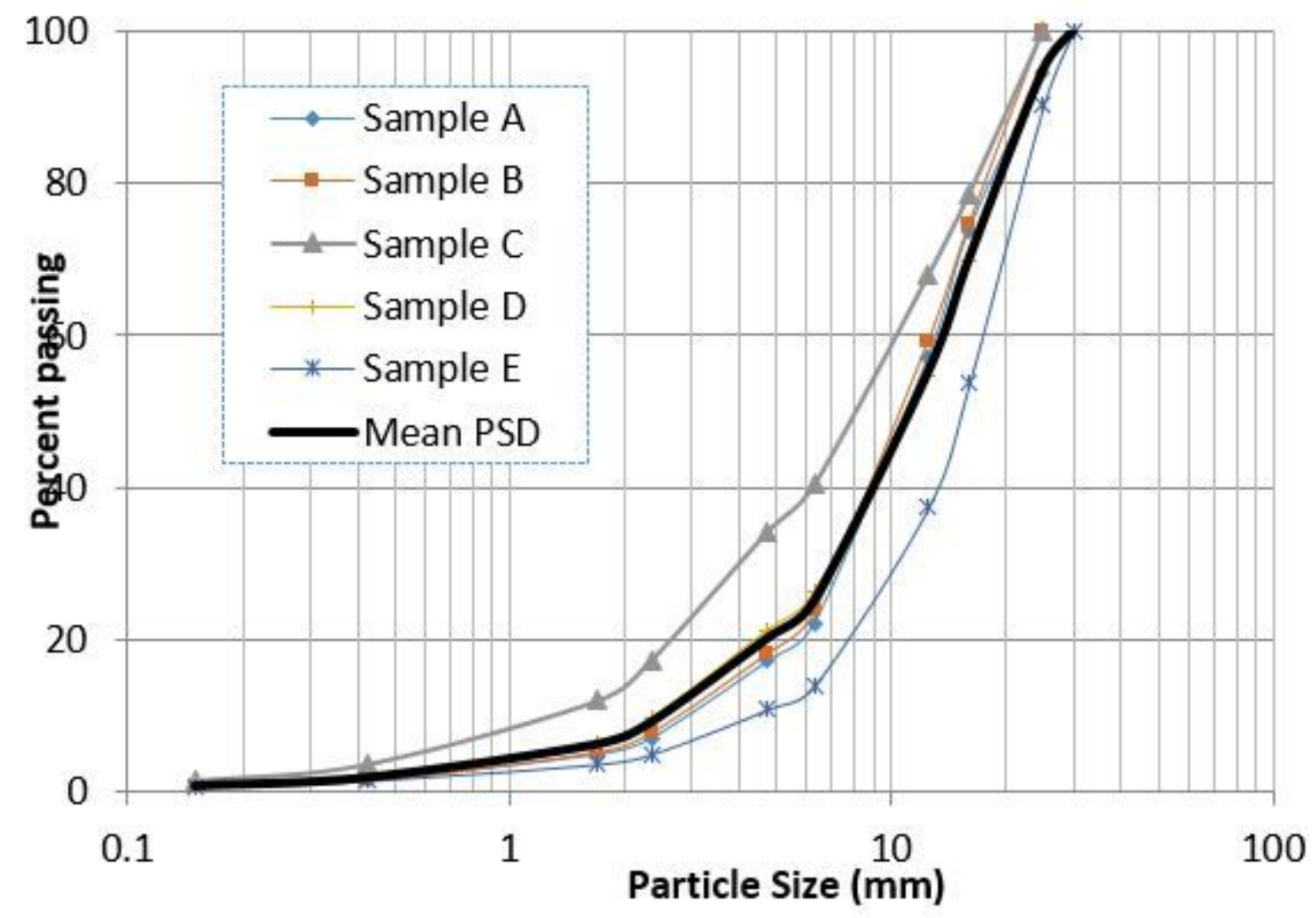

Figure 2

Particle size distribution of several samples and Mean PSD used for preparing shear box specimens

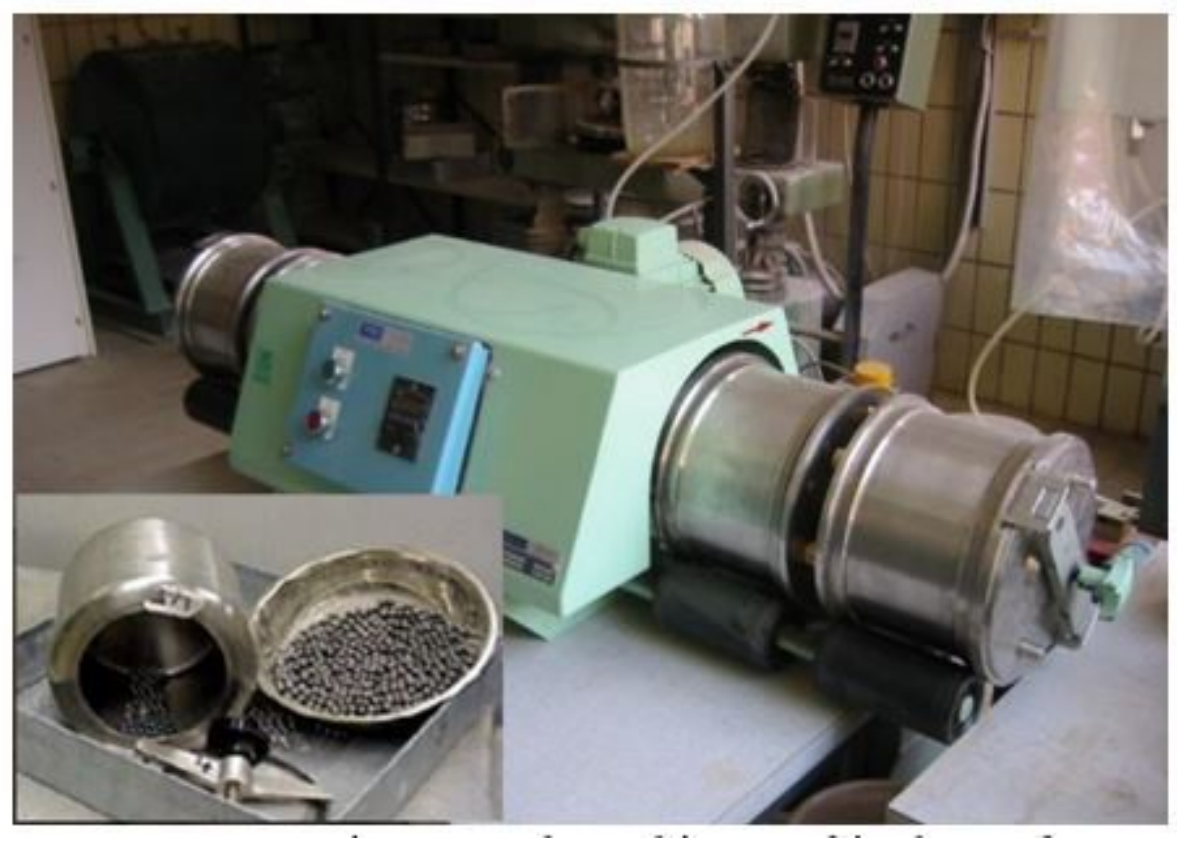

Figure 3

Micro-Deval Machine used in the study 


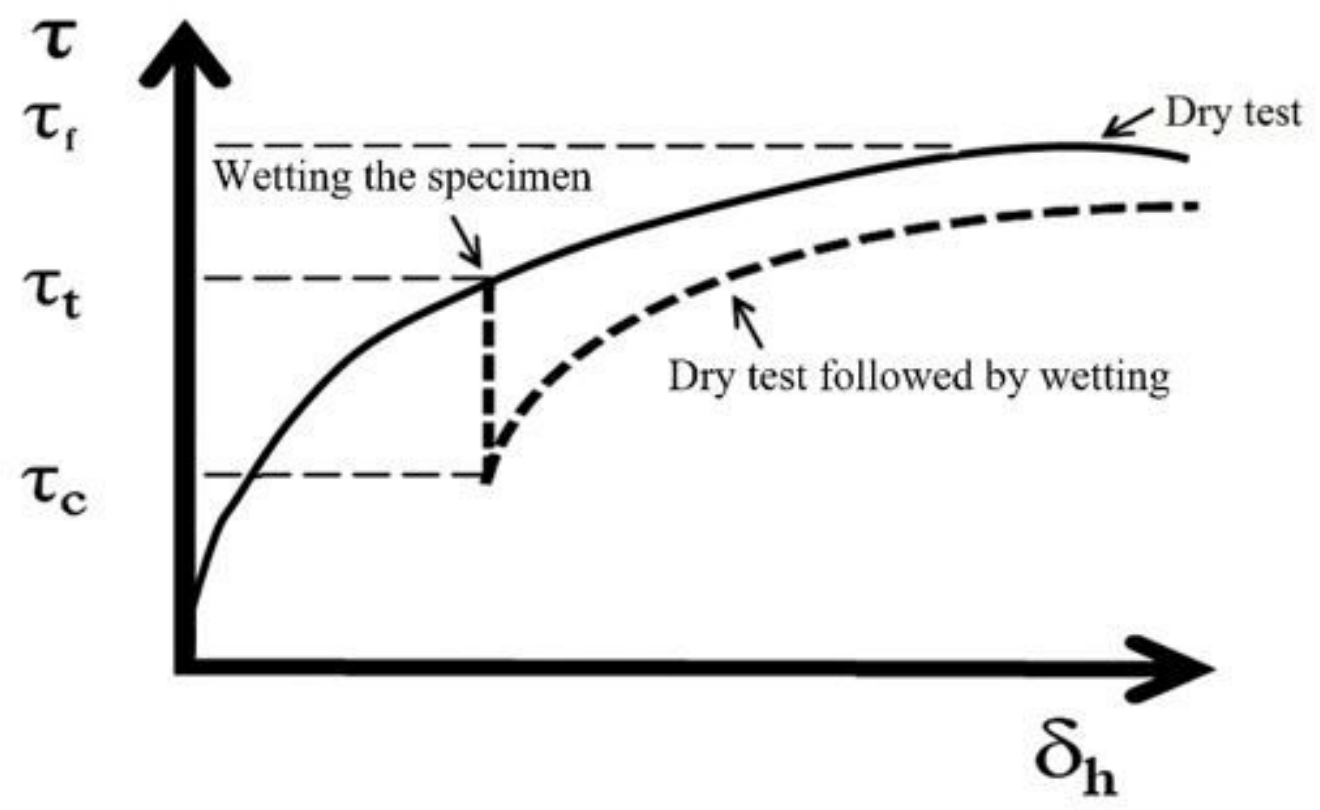

(a)

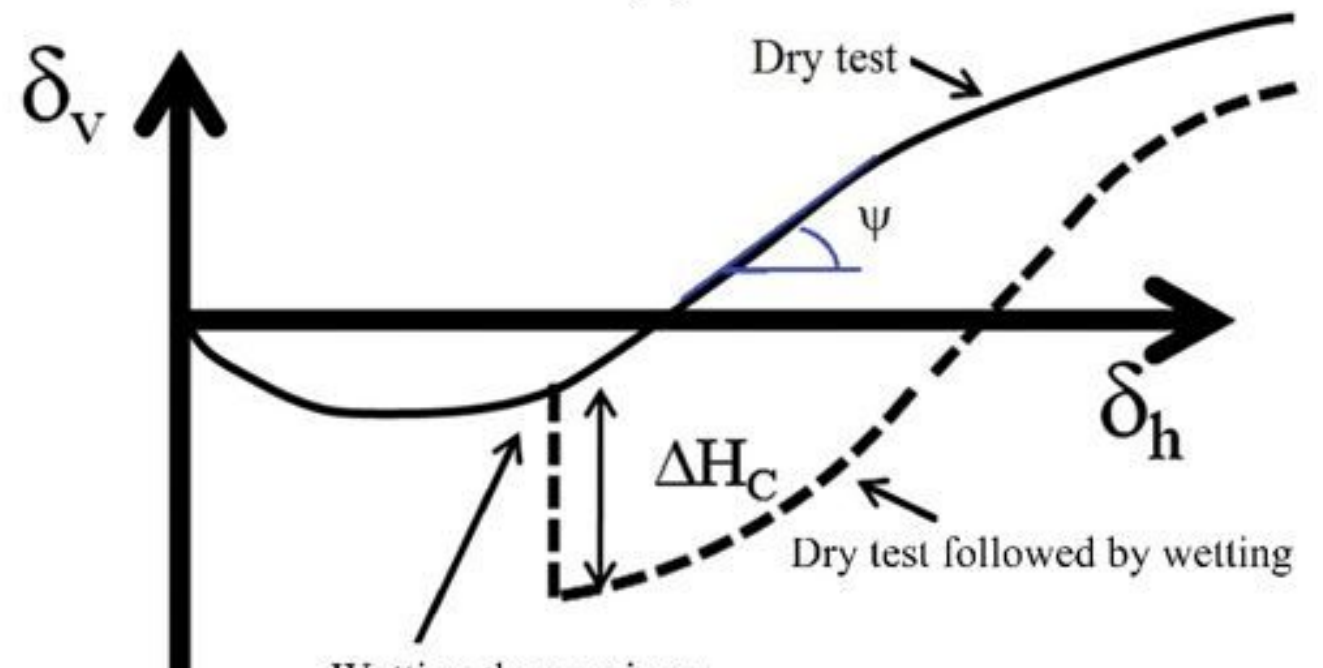

Wetting the specimen

(b)

Figure 4

Typical curves for in dry test and dry followed by wetting. a shear stress-shear displacement. b vertical displacement-shear displacement 


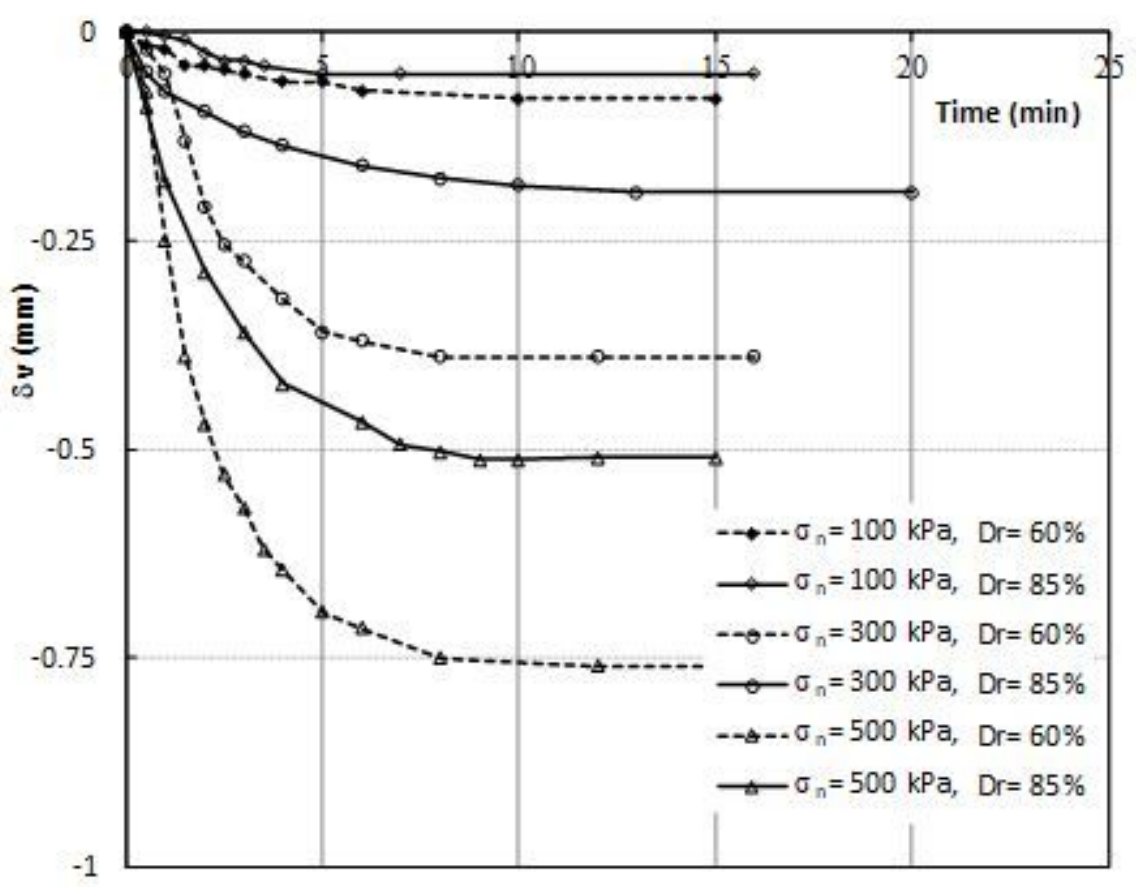

(a)

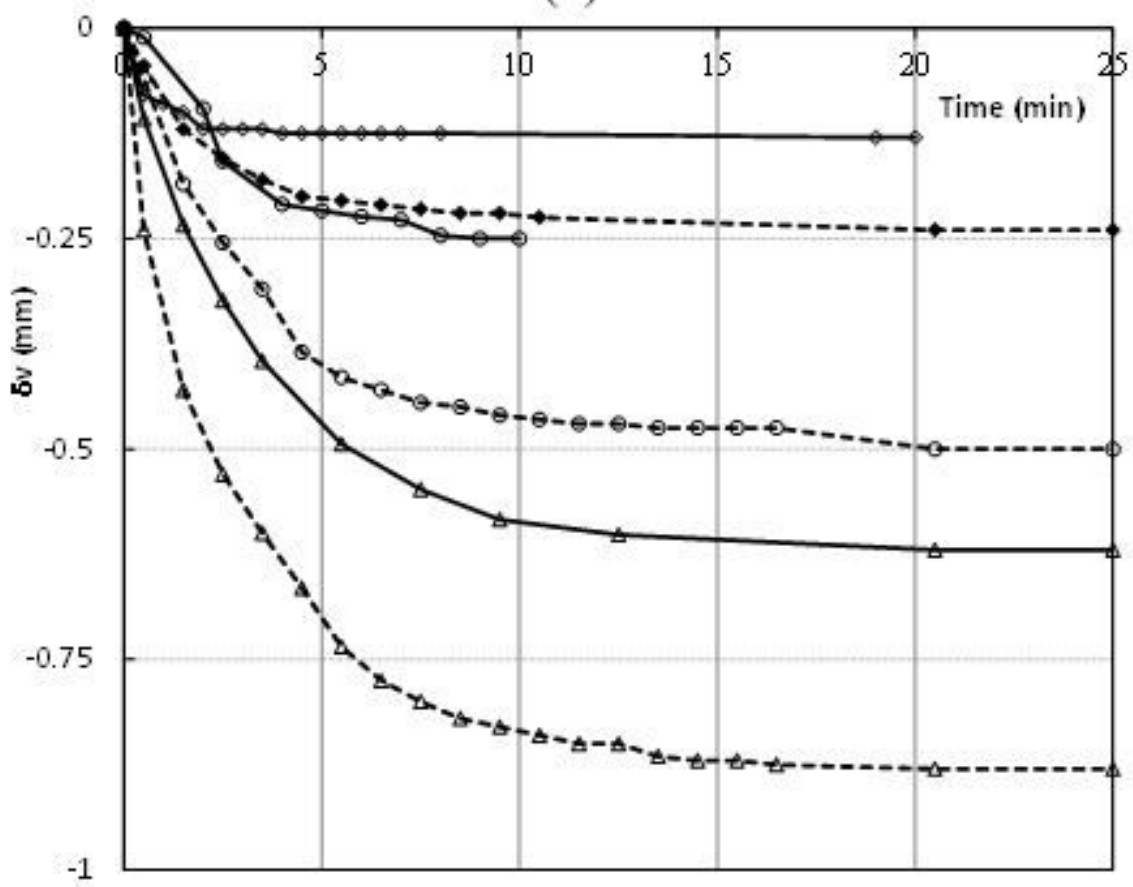

(b)

Figure 5

Effect of relative density and normal stress on the collapse settlement. a $S L=0$. b $S L=50 \%$ 


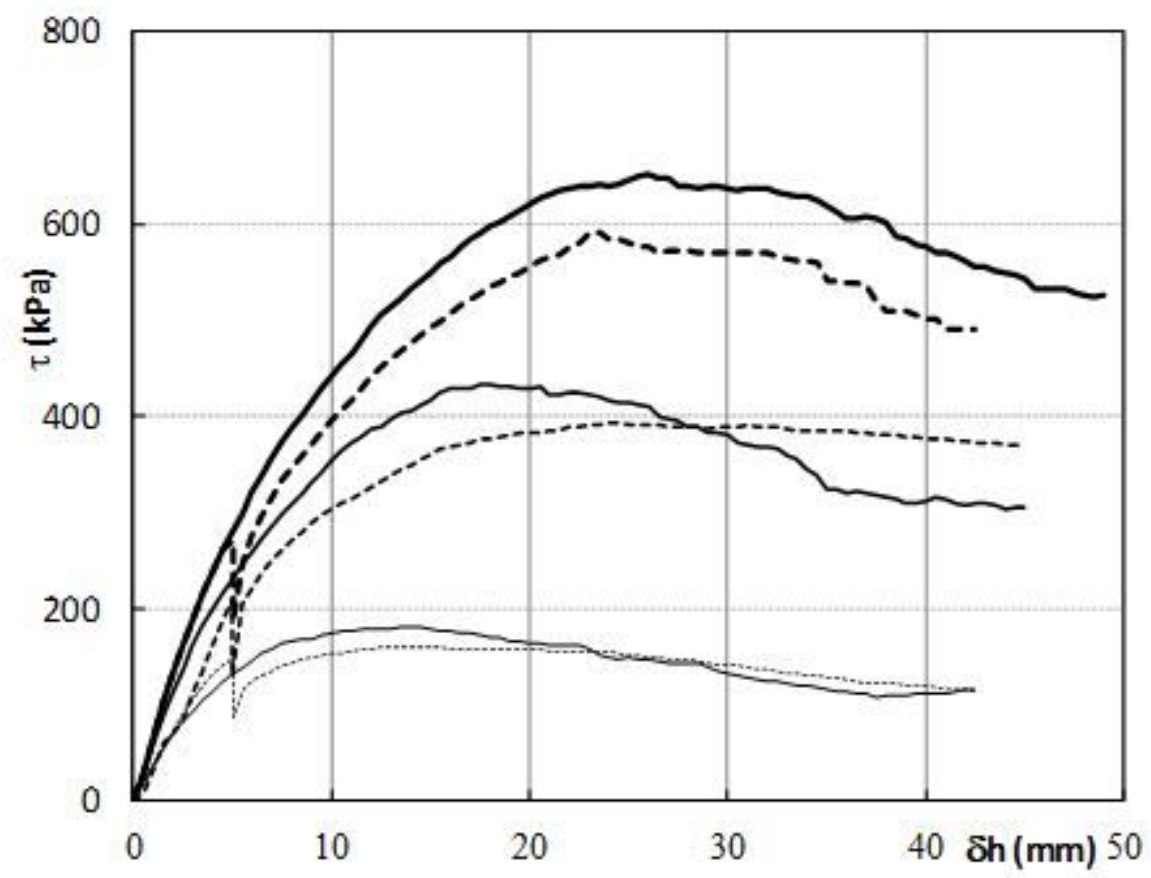

(a)

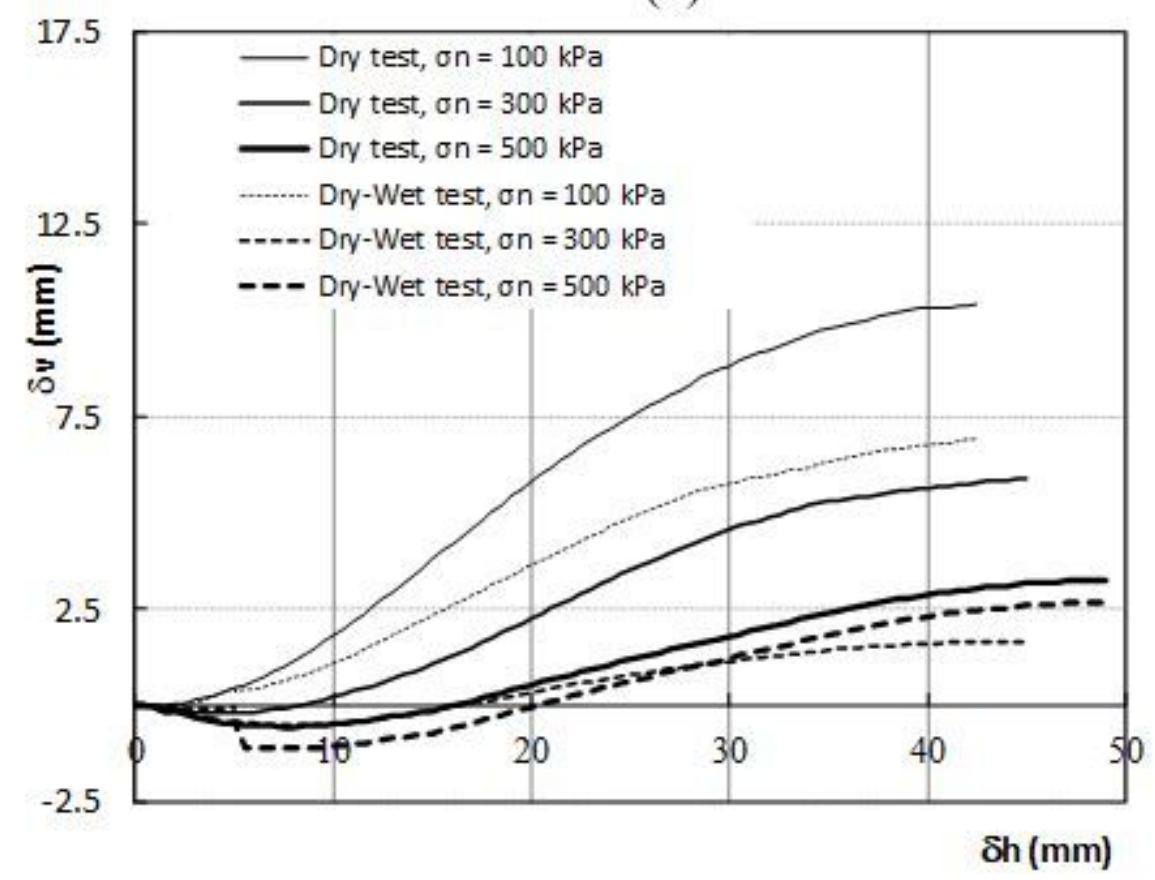

(b)

\section{Figure 6}

Direct shear test results on specimens with angular particle shapes $(\mathrm{Dr}=85 \%)$. a shear stress-shear displacement. b vertical displacement-shear displacement 


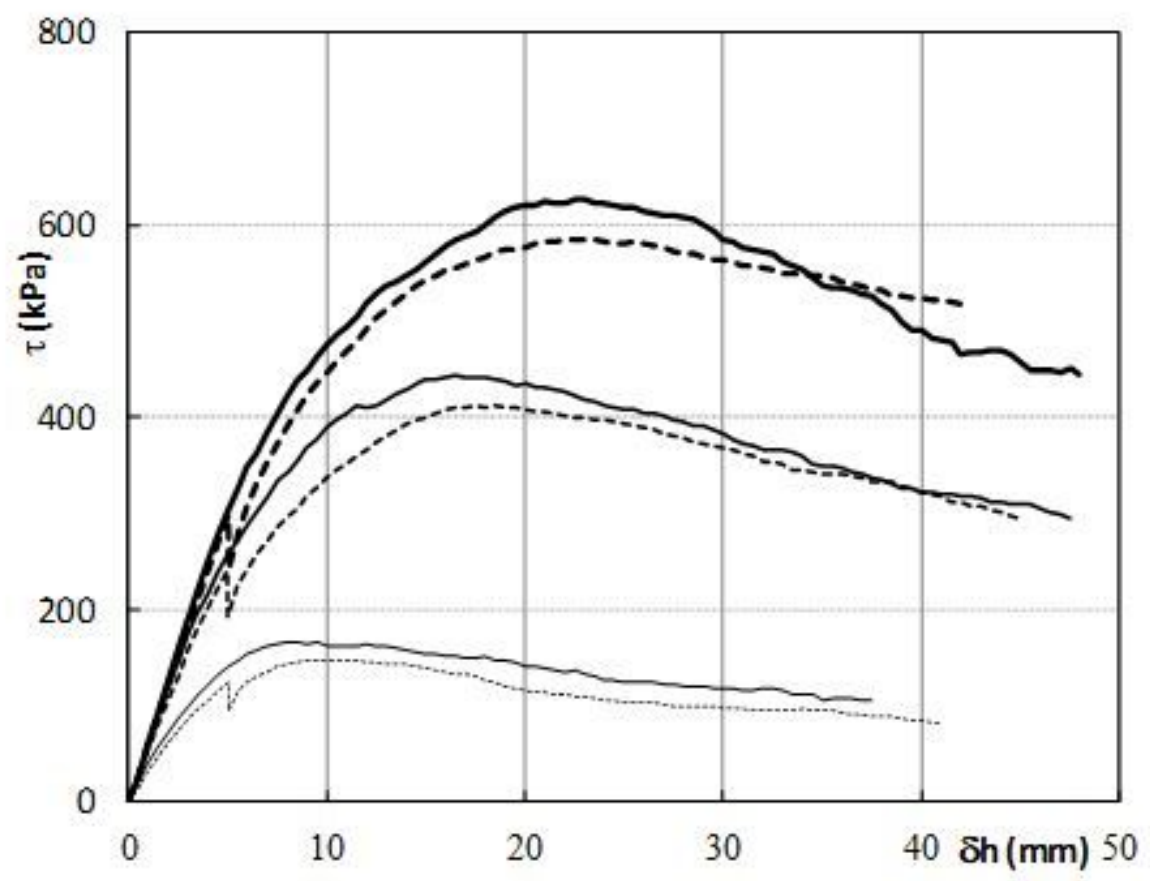

(a)

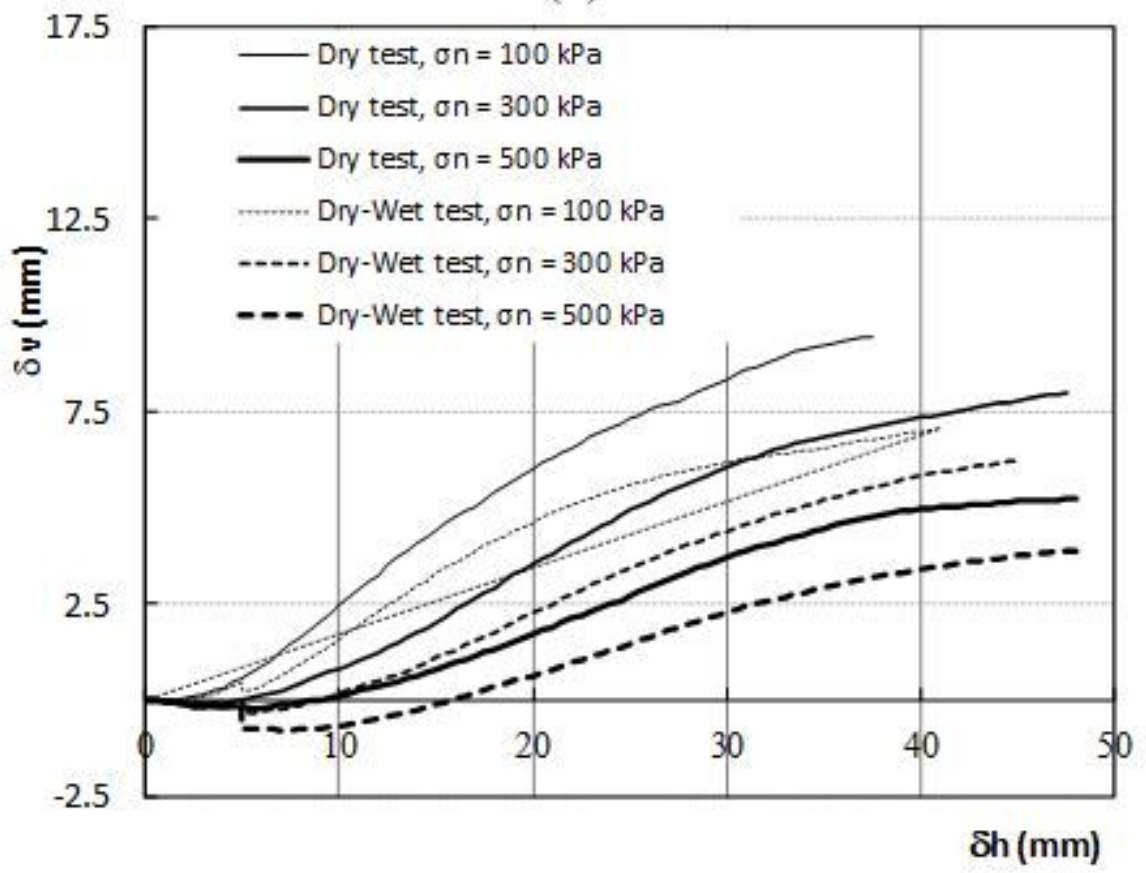

(b)

Figure 7

Direct shear test results on specimens with sub-angular particle shapes $(\mathrm{Dr}=85 \%)$. a shear stress-shear displacement. b vertical displacement-shear displacement 


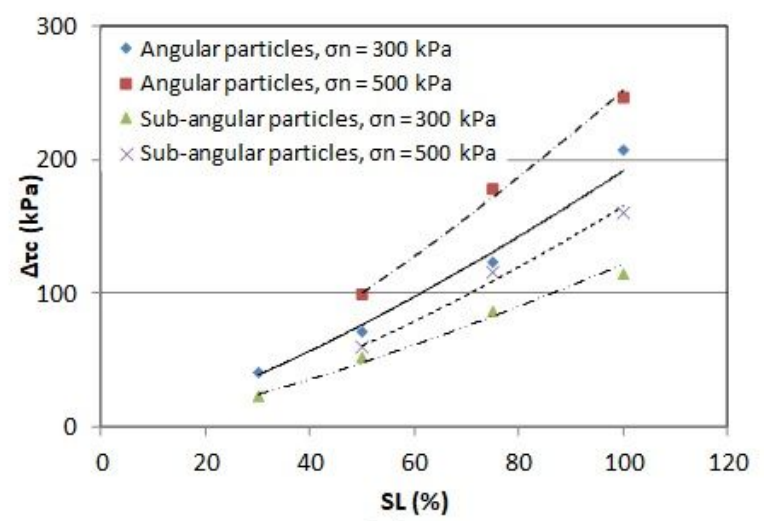

(a)

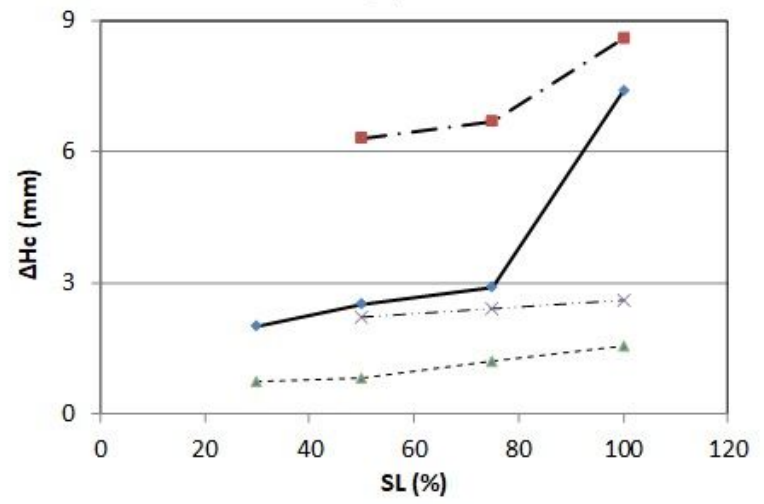

(b)

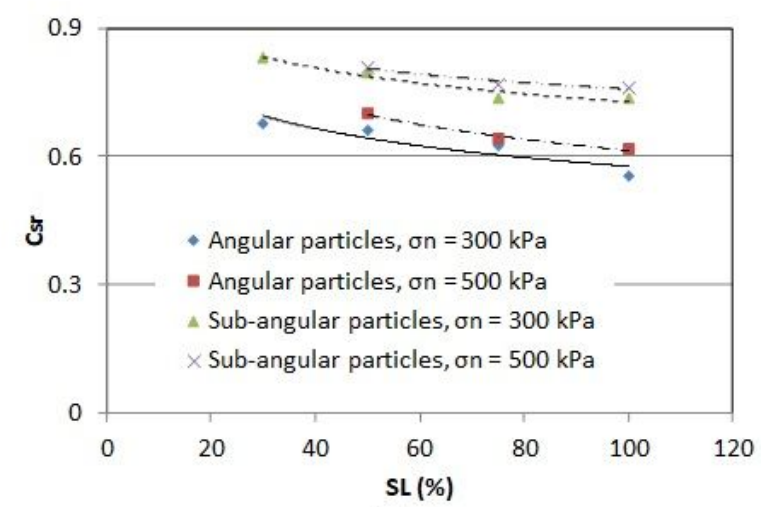

(c)

\section{Figure 8}

Effect of particle shape on a stress relaxation, b collapse settlement and c Coefficient of stress recovery 


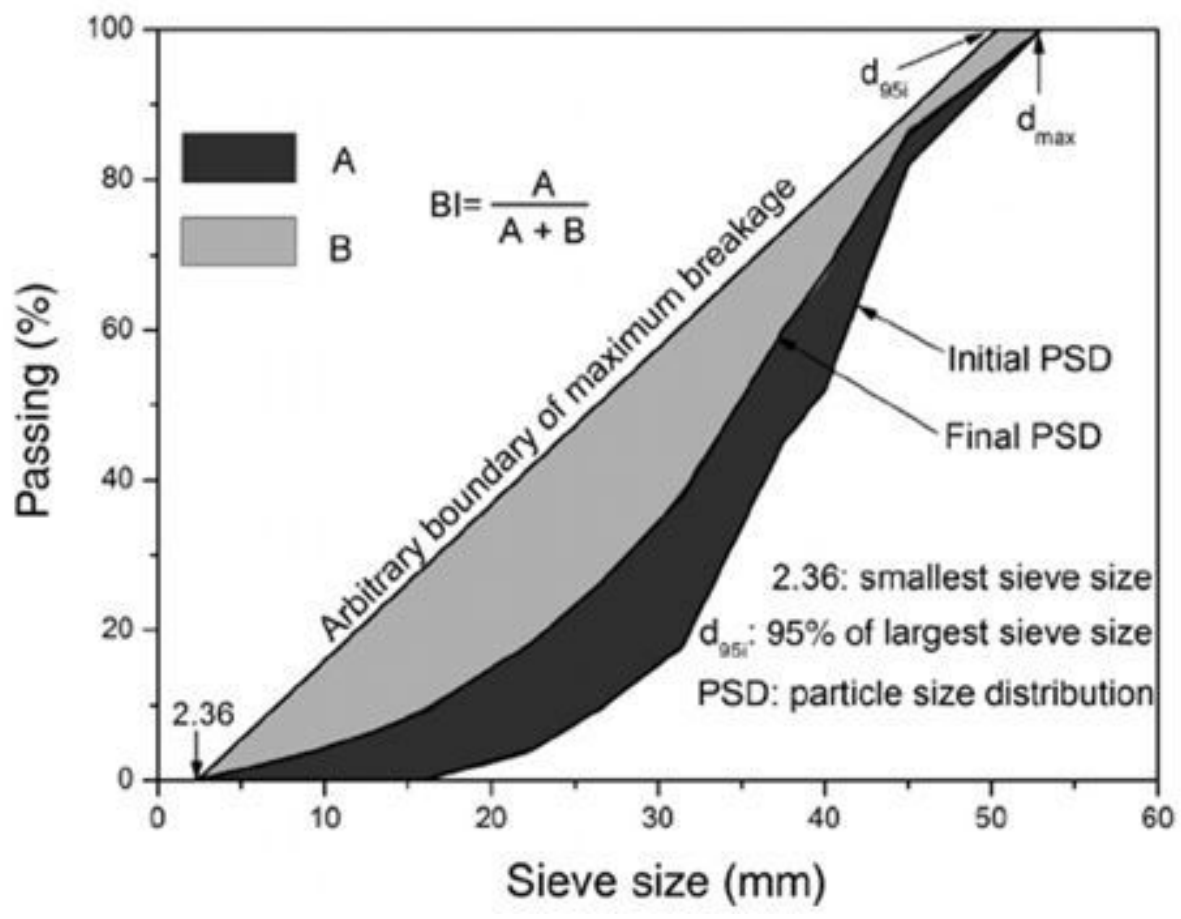

Figure 9

Definition of particle breakage index38

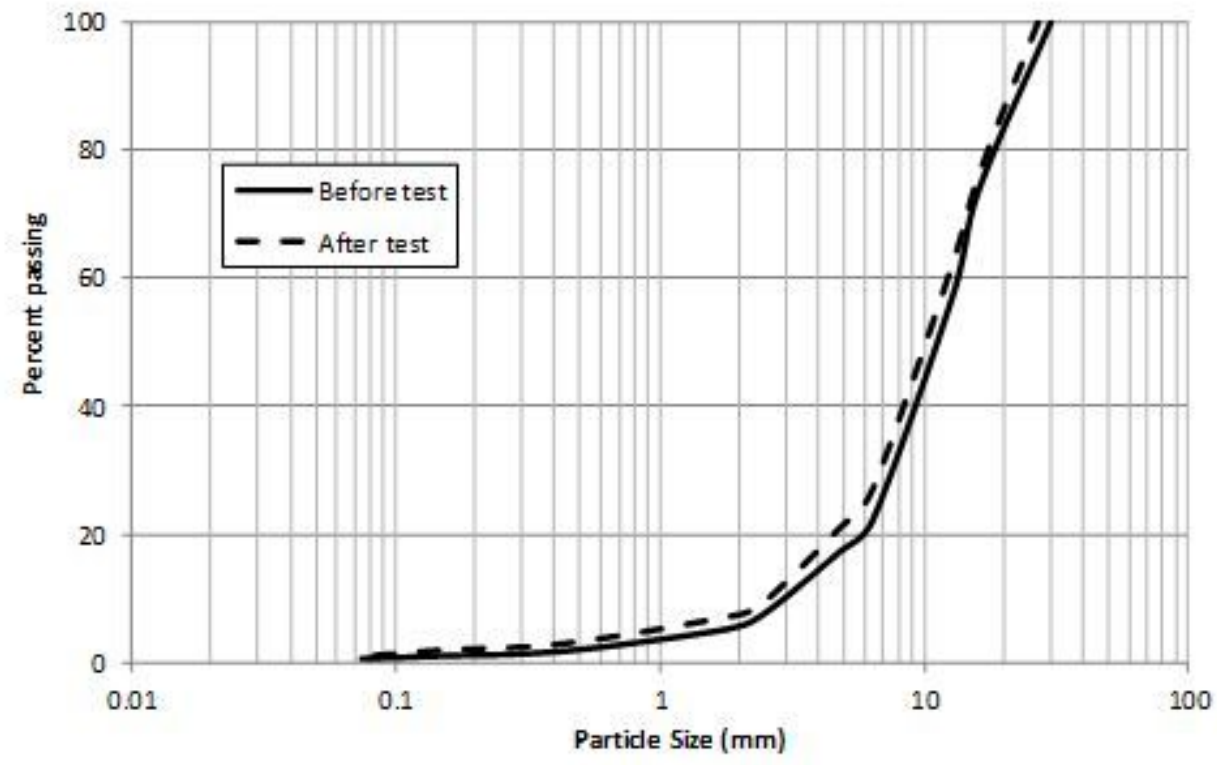

Figure 10

please see the manuscript file for the full caption 


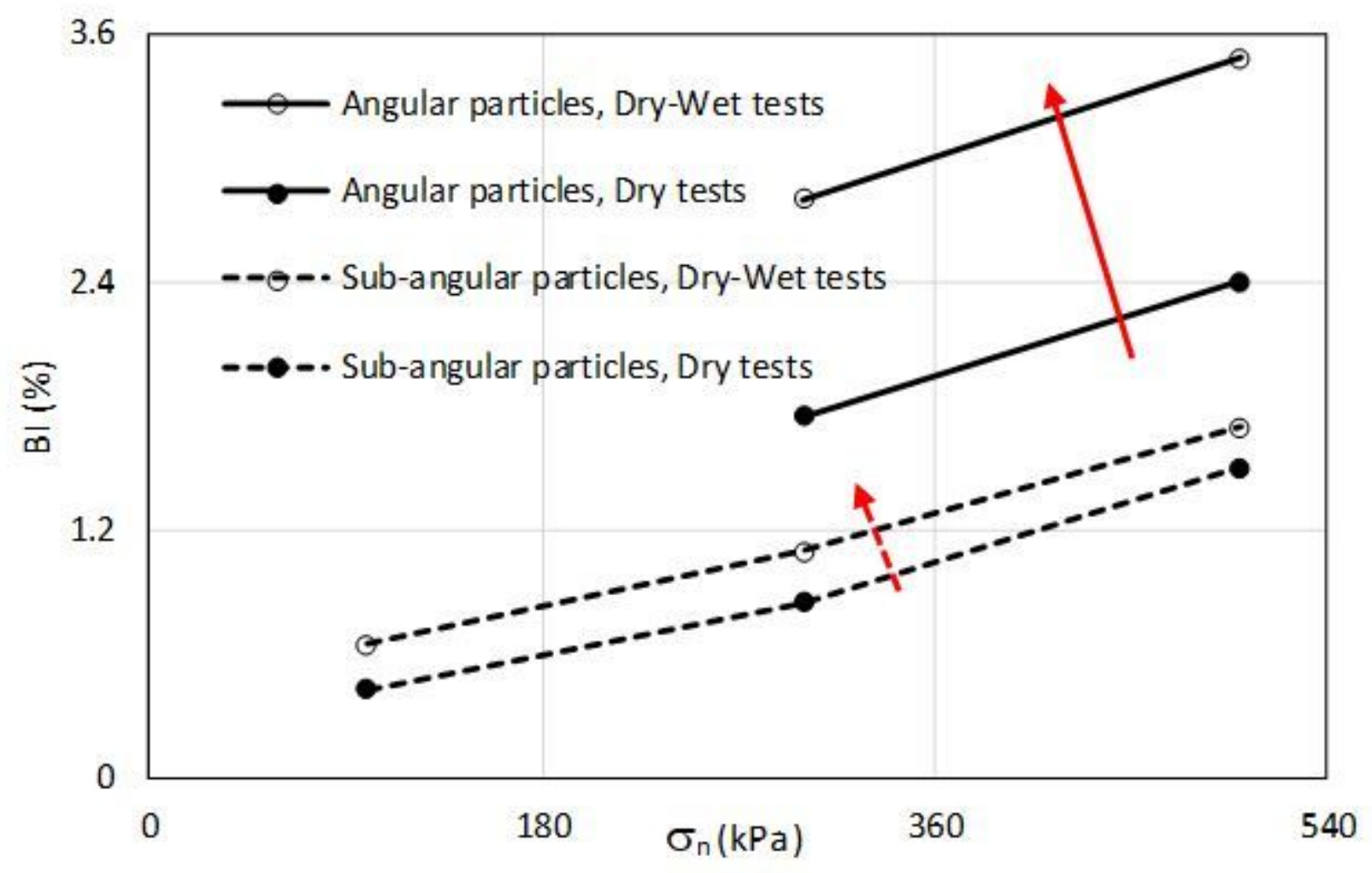

Figure 11

Variation of particle breakage index with normal pressure 